\title{
Dynamics and viscosity of 'a'a and pahoehoe lava flows of the 2012-2013 eruption of Tolbachik volcano, Kamchatka (Russia)
}

\author{
Alexander Belousov $^{1}$ (D) Marina Belousova $^{1}$ \\ Received: 10 April 2017 / Accepted: 23 November 2017 \\ (C) Springer-Verlag GmbH Germany, part of Springer Nature 2017
}

\begin{abstract}
The 2012-2013 flank eruption of Tolbachik volcano (Kamchatka) lasted 9 months and produced $0.54 \mathrm{~km}^{3}$ of basaltic trachyandesite lava, thus becoming one of the most voluminous historical lava effusions of basic composition in subductionrelated environments globally. From March to July 2013, the volcano monotonously erupted lava of constant composition $\left(\mathrm{SiO}_{2}=52 \mathrm{wt} \%\right)$ with a nearly stable effusion rate of $18 \mathrm{~m}^{3} / \mathrm{s}$. Despite the uniform eruptive and emplacement conditions, the dominant style of lava propagation throughout that time gradually changed from ' $a$ 'a to pahoehoe. We report results of instrumental field measurements of the 'a'a and pahoehoe flow dynamics (documented with time-lapse cameras) as well as the lava viscosity determined by flow rate and shear stress (using penetrometer) methods. Maximal propagation velocities of the 'a'a fronts ranged from 2 to $25 \mathrm{~mm} / \mathrm{s}$, and those of the pahoehoe from 0.5 to $6 \mathrm{~mm} / \mathrm{s}$. The flow front velocities of both lava types experienced short-period fluctuations that were caused by complex flow mechanics of the advancing flow lobes. Minimal viscosities of lava of the 'a'a lobes ranged from $1.3 \times 10^{5}$ to $3.3 \times 10^{7} \mathrm{~Pa}$ s (flow rate method), and those of the pahoehoe from to $5 \times 10^{3}$ to $5 \times 10^{4} \mathrm{~Pa} \mathrm{~s}$ (shear stress method). Our data include the first ever measured profiles of viscosity through the entire thickness of actively advancing pahoehoe lava lobes. We have found that both the ' $\mathrm{a}$ ' a and pahoehoe flows were fed by identical parental lava, which then developed contrasting rheological properties, owing to differences in the process of lava transport over the ground surface. The observed transition from the dominant 'a'a to the dominant pahoehoe propagation styles occurred due to gradual elongation and branching of the lava tube system throughout the course of the eruption. Such evolution became possible because the growing lava field, composed of semisolidified flows, provided an environment for shallow subsurface intrusions and internal migrations of lava that, with time, developed into branches of the lava tube system. Based on our data, we propose phenomenological models of the 'a'a and pahoehoe flow mechanics.
\end{abstract}

Keywords Lava flow velocity Viscosity of lava $\cdot$ 'A'a $\cdot$ Pahoehoe $\cdot$ Tolbachik volcano

\section{Introduction}

Viscosity (a measure of a fluid's resistance to flow) is one of the key characteristics that determine the dynamics of lava flows (e.g., Gauthier 1973; Walker et al. 1973; Papale 1999;

Editorial responsibility: J. Taddeucci

Electronic supplementary material The online version of this article (https://doi.org/10.1007/s00445-017-1180-2) contains supplementary material, which is available to authorized users.

Alexander Belousov

belousov@mail.ru

1 Institute of Volcanology and Seismology, Piip boulevard 9, Petropavlovsk-Kamchatsky, Russian Federation 683006
Griffiths 2000; Sparks 2004; Dingwell 2006). There are two different styles of propagation of a lava flow front (Macdonald 1953; Self et al. 1998; Harris et al. 2017). 'A'a and block lava flows propagate as thick massive lobes that resemble a conveyor belt (e.g., Krauskopf 1948; Macdonald 1953; Lipman and Banks 1987; Francis 1993; Harris and Rowland 2001). The molten inner part of such flows is enveloped and thermally insulated by a layer of fragmented (autobrecciated) solidified lava. This flow style is characteristic for viscous lavas of evolved compositions, but in some cases (when shear rate of lava is high enough, e.g., rapid flows on steep slopes), it is also common for fluid lavas of basic compositions (e.g., Rowland and Walker 1990). Lava flows of the pahoehoe type propagate by a completely different style: numerous small short-lived lava lobes slowly ooze from multiple locations chaotically scattered along a relatively thin and broad flow front (e.g., 
Hon et al. 1994, Self et al. 1998; Gregg and Keszthelyi 2004). Due to surface cooling and degassing, each pahoehoe lobe quickly develops a thin outer layer (viscoelastic skin) with a higher viscosity than the internal lava. Initially, the skin is flexible and, while the lobe propagates, undergoes various deformations: stretches, folds, etc. The skin gradually solidifies with time and forms brittle crust that preserves the deformation-induced intricate surface morphologies (e.g., ropy, entrail-like, etc.). Beneath the solidified crust that has low thermal conductivity (e.g., Wilson and Head 2007), lava remains fluid and hydraulically connected with the lava source for an extended time causing slow inflation of the encrusted pahoehoe lobes that lasts for hours-days after their initial emplacement (e.g., Hon et al. 1994; Anderson et al. 1999; Hoblitt et al. 2012). Pahoehoe flows are formed only by fluid lavas of basic compositions.

Cases have been observed where one style of lava propagation turns into another (commonly pahoehoe to 'a'a) during the course of one eruption (e.g., Rowland and Walker 1990). When no substantial changes of the lava viscosity were detected, the observed transitions were thought to involve a critical relation between viscosity and shear strain (e.g., Peterson and Tilling 1980). Kilburn (1993) suggested that interactions between the fluid core and the solidified crust determined a flow's morphological and dynamical evolution distinguishing core-dominated ('a'a) and crustal-dominated (pahoehoe) lava flows. Transitions between these two types depend on lava discharge rate, underlying slope, and either the velocity of the flow front or the flow thickness (e.g., Soule et al. 2004).

One of the main field methods to estimate the viscosity of lava is based on the mean velocity of lava flowing in a channel of known depth (Nichols 1939; Walker 1967) using Jeffreys' equations (Jeffreys 1925). This method (here termed the "flow rate method") has been applied either to lava flowing in open channels or to frontal regions of flow lobes and has been used at many effusive eruptions worldwide (Fig. 1 and references therein, as well as Online Resource Table ESM 1). However, this simple method provides only approximate estimations of overall, or apparent, viscosity of lava flows (Lev and James 2014). More challenging are direct instrumental measurements of lava viscosity using various, commonly custombuilt viscometers. This method (here termed the "shear stress method") allows the measurement of viscosity at discrete points of a lava flow. There are publications reporting such measurements for lava flows on Surtsey (Einarsson 1966), Kilauea (Shaw et al. 1968; Pinkerton et al. 1995), Etna (Gauthier 1973; Pinkerton and Sparks 1978; Pinkerton and Norton 1995), and Klyuchevskoy (Panov et al. 1988) (Fig. 1 and Online Resource Table ESM 1). The studies show that values of viscosity, even at one lava flow, can span many orders of magnitude, where viscosity strongly changes between the external and internal parts of a flow, as well as with its travel time and distance from the eruption source (Shaw et al. 1968; Fink and Zimbelman 1986; Moore 1987; Naranjo et al. 1992; Soldati et al. 2016).

Obvious difficulties accompanying direct measurements of lava viscosity can be avoided if silicate melts are studied in laboratory conditions (Dingwell 2006 and references therein). These data show that the viscosity of magmatic melts strongly depends on their composition (mostly silica content)as well as transient parameters such as temperature and content of volatiles and crystals (e.g., Rowland and Walker 1988; Kilburn 2000). The laboratory data, however, have limited application to natural systems because in real magma/lava the melt phase contains admixture of solid particles (crystals, fragments of solidified autobrecciated lava, various xenoliths) and gas bubbles will nonlinearly change its overall rheology (Manga and Loewenberg 2001; Giordano et al. 2008; Petford 2009; Vona
Fig. 1 Published data on the viscosity of lava flows of basic compositions worldwide measured with the flow rate and shear stress methods compared with the viscosity data for the 2013 lava of Tolbachik. Details in Tables 1 and 2 and Online Resource Table ESM 1

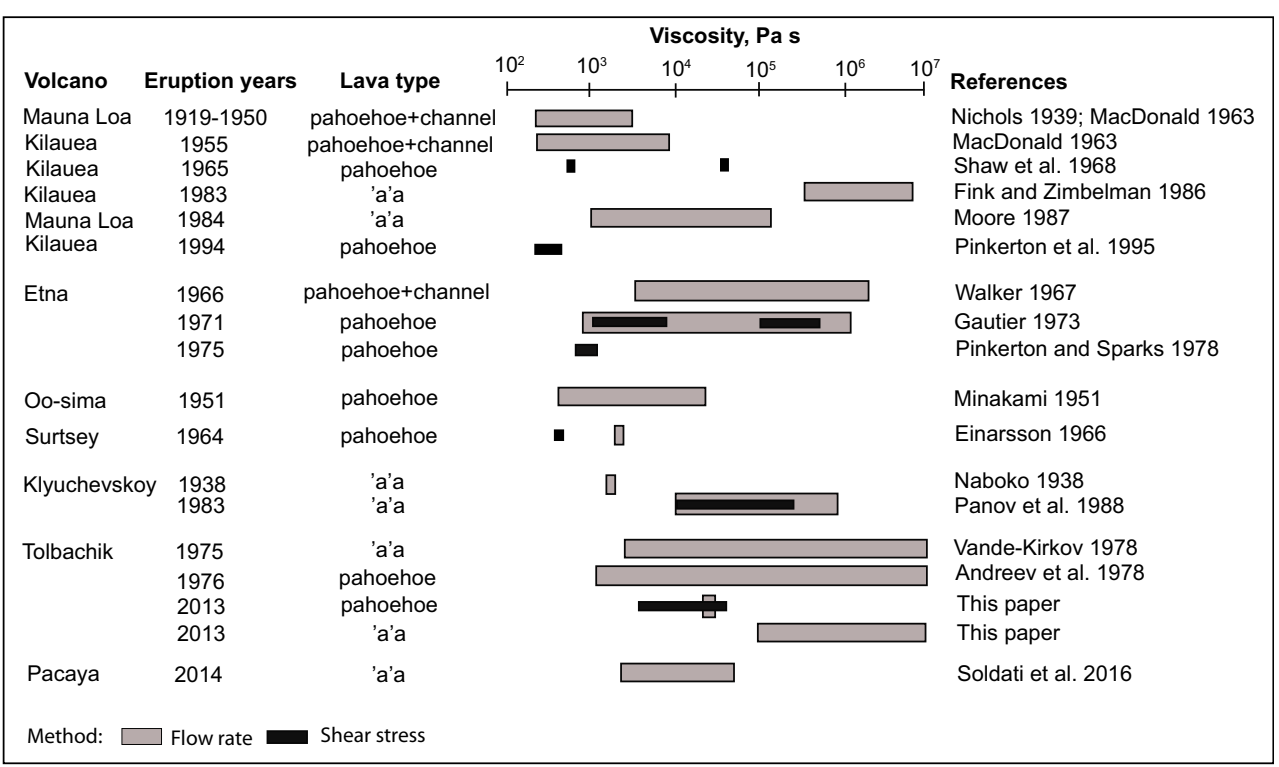


et al. 2011). Numerical modeling of rheological properties of such multiphase fluid systems is promising but needs verification with field ground truth data, the lack of which currently presents a significant problem (e.g., Proussevitch and Sahagian 1998; Saar et al. 2001).

Styles and dynamics of lava propagation are also controlled by the lava discharge rate and various external factors, the most significant of which is local slope (e.g., Soldati et al. 2016 and references therein). Eruptions, that simultaneously produce 'a'a and pahoehoe flows of identical composition, provide a unique opportunity to understand the role of noncomposition-related factors on lava propagation dynamics. The 2012-2013 eruption of Tolbachik was one such opportunity.

Plosky Tolbachik (3065 m asl) is one of the most active volcanoes in Kamchatka (https://volcano.si.edu/volcano.cfm? $\mathrm{vn}=300240$ ) with frequent summit and three flank eruptions in the twentieth and twenty-first centuries, which took place in 1941, 1975-1976, and 2012-2013 (Piip 1946; Fedotov and Markhinin 1983; Belousov et al. 2015). Tolbachik's last eruption occurred in 2012-2013 and was one of the most voluminous historical lava effusions of basic composition in subduction-related environments globally, where lava flows of both 'a' a and pahoehoe types with volume $0.54 \mathrm{~km}^{3}$ covered an area of $36 \mathrm{~km}^{2}$ (Dvigalo et al. 2014, in preparation). In this paper, we report the results of field instrumental measurements of the lava flow dynamics (using time-lapse photography) and viscosity (using flow rate and shear stress methods). The data include first ever measured profiles of viscosity. This was obtained using a custom-built penetrometer through the entire thickness of actively advancing and inflating pahoehoe lava lobes. Based on these new data, we propose phenomenological flow models for 'a'a and pahoehoe flow mechanics.

\section{The 2012-2013 eruption of Tolbachik}

\section{General description of the eruption chronology}

The 2012-2013 eruption of Hawaiian-Strombolian type began on November 27, 2012, on the southern flank of stratovolcano Plosky Tolbachik along a 6-km-long radial fissure that extended between 1460 and $2358 \mathrm{~m}$ asl (Dvigalo et al. 2014, in preparation; Belousov et al. 2015). During the initial stage of the eruption, lava fountaining and intense effusive activity occurred from multiple locations along the entire length of the eruptive fissure. Until November 29, the time averaged discharge of lava was $440 \mathrm{~m}^{3} / \mathrm{s}$ and it declined to $140 \mathrm{~m}^{3} / \mathrm{s}$ by the beginning of December (the calculations based on the lava field volumes measured with aerial photogrammetric surveys). This activity formed the Vodopadnoye lava flow field (length $8.5 \mathrm{~km}$, area $6.17 \mathrm{~km}^{2}$, volume $0.043 \mathrm{~km}^{3}$ ) and a major part of the Leningradskoye lava flow field (length $17.8 \mathrm{~km}$, area $22.44 \mathrm{~km}^{2}$, volume $0.397 \mathrm{~km}^{3}$ ) (Fig. 2a). Both lava fields were composed mostly of ' $a$ 'a flows. After December 8 , the eruption concentrated in the lower part of the fissure at $1740 \mathrm{~m}$ asl elevation where the Naboko scoria cone began to grow. During 2013, this cone, with its two intracrater lava ponds, became the source of an 8month-long effusion of lava that was initially fed by an open channel, and later became tube-fed at a nearly steady time averaged discharge rate of approximately $18 \mathrm{~m}^{3} / \mathrm{s}$ (the calculation based on the lava flow field volumes measured with aerial photogrammetric surveys on December 13, 2012; March 6, 2013; and June 5, 2013, by Dvigalo et al. 2014, in preparation). This long-term effusion completed the formation of the Leningradskoye field and later built the Toludskoye field. This third lava field (length $4.3 \mathrm{~km}$, area $8.4 \mathrm{~km}^{2}$, volume $0.1 \mathrm{~km}^{3}$ ) was composed of 'a'a, which accounted approximately $30 \%$ of the lava flow field area, plus pahoehoe flows and various transitional lava types which accounted for the remaining $70 \%$ of the lava flow field area. In August, the discharge rate decreased to $2.4 \mathrm{~m}^{3} / \mathrm{s}$, and on August 23, 2013, the effusive activity ceased and lava drained from the lava tube system as well as from the intracrater lava ponds. During the final stage of the eruption, weak Strombolian activity within the Naboko cone crater continued until September 5, 2013, when the eruption ceased completely (Belousov et al. 2015). The eruption products were trachyandesite. During the first days of the eruption, the $\mathrm{SiO}_{2}$ content was $54 \mathrm{wt} \% \mathrm{SiO}_{2}$, which then decreased to $52 \mathrm{wt} \%$ and remained constant until cessation of the eruption (Volynets et al. 2015).

\section{Observations of the Toludskoye lava flow field}

Our measurements were completed during the formation of the Toludskoye lava flow field (Fig. 2b) as part of three field campaigns in March-April, May, and July 2013. During that period, the $\mathrm{SiO}_{2}$ content of the lava and the time-averaged discharge rate remained constant, correspondingly $52 \mathrm{wt} \%$ and $18 \mathrm{~m}^{3} / \mathrm{s}$ (Dvigalo et al. 2014; Volynets et al. 2015). The eruption was characterized by frequent Hawaiian/ Strombolian-type lava fountains occurring from two lava ponds, filling the craters of the developing Naboko scoria cone (Fig. 4a). From these ponds, lava was transported underground through a system of lava tubes. The system of lava tubes progressively elongated and branched with time. Simultaneously with the lava tube elongation and branching, the gradual transition of the dominant lava emplacement style from 'a'a to pahoehoe occurred.

In March-April, 'a'a flows represented the dominant style of lava propagation and emplacement (Belousov et al. 2015). During this period, lava tubes were 3-10 m wide and approximately $1 \mathrm{~km}$ long. Lava effused from a vent at $1500 \mathrm{~m}$ asl and then flowed in open channels that commonly had overhanging 

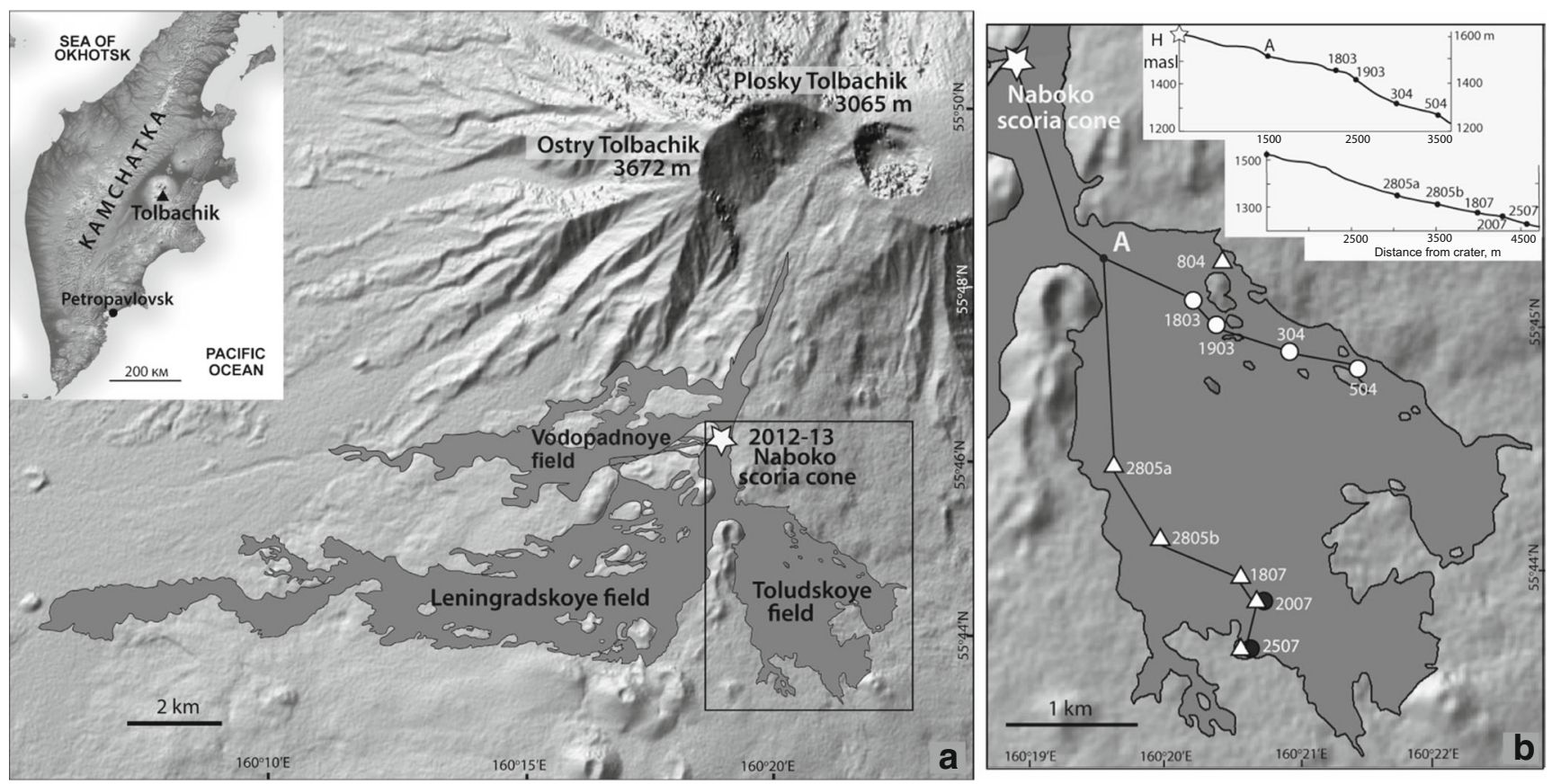

Fig. 2 Sketch map of the areal distribution of the lava flows of the 2012 2013 eruption of Tolbachik volcano (based on Fig. 1 of Volynets et al. 2015). a General scheme showing the three main lava fields of the eruption. Square outlines the Toludskoye lava field studied in this paper and enlarged in $\mathbf{b}$. The inset shows the location of Tolbachik volcano on the Kamchatka Peninsula. b Toludskoye lava field with points where measurements of the lava dynamics and viscosity were completed: 'a'a flow dynamics and viscosity by the flow rate method (white circles), pahoehoe dynamics and viscosity by the flow rate method (black circles), and viscosity of pahoehoe flows by the shear stress method (white triangles). Numbers correspond to the dates of measurements (day/month) as well as to numbers in Tables 1 and 2 and Figs. 5, 7, 8, and 9. Topography profiles from the 1:50,000 map before the eruption along the approximate paths of the lava flows in the right upper corner; vertical scale is exaggerated by a factor of 2

formed 'a'a lobes (Fig. 4a). During May, the system of lava tubes grew to more than $3 \mathrm{~km}$ in length. Lava effused onto the surface at many locations scattered across the Toludskoye lava flow field covering 'a'a lava flows that had been emplaced during April-May. In May, the pahoehoe flows propagated mostly over the clinker breccia of the previously deposited 'a'a flows (Fig. 3c). In July, the lava tube system grew to over $4 \mathrm{~km}$ long. The style of effusive activity was similar to that in May. Lava flows advanced mostly along a substrate of ancient lavas and scoria fallout deposits with sparse patches of grass and dwarf shrubs (Fig. 3d).

Detailed investigations of the petrology and geochemistry of the erupted products were conducted by Volynets et al. (2015), Plechov et al. (2015), and Portnyagin et al. (2015). These studies show that the 'a'a and pahoehoe lavas had identical chemical and mineral compositions which did not change throughout the formation of the Toludskoye field. The lavas were subaphyric basaltic trachyandesites (52 wt $\% \mathrm{SiO}_{2}$ ) with very rare phenocrysts of plagioclase, olivine, and clinopyroxene. Lava sampled in fluid state (with temperatures $>1000{ }^{\circ} \mathrm{C}$ ) and then chilled in the air contained transparent brownish light-yellow interstitial glass (sideromelane). Samples that gradually cooled and crystallized in situ inside the flows had opaque devitrified groundmass (tachylite). The interstitial glass contained 
Fig. 3 Active lava flows of the 2013 eruption of Tolbachik volcano. a Lava exiting the tube $7 \mathrm{~m}$ wide outlet and flowing in the open channel on March 19 (a FLIR image of the same flow is shown in Fig. 4b). b Front of 'a'a lava advancing over snow on March 18 (propagation of the flow is given as Online Resource Video ESM 3). c Pahoehoe flow front advancing over 'a'a flows deposited in February-April; May 28. d Secondary pahoehoe flow extruding out of a stagnated 'a'a flow and advancing over ancient lava with sparse patches of grass and dwarf shrubs on July 24 . e Viscosity measurement with the penetrometer at an active pahoehoe lobe forming by rear growth mode on July 25, 2013 (see the section "Methodology" for the method of measurement and Online Resource Video ESM 2). In the background, a chain of lobes with a longitudinal cleft structure forming by slow inflation. Photos a to $\mathbf{d}$ by A. Belousov; photo e by Yu. Frolova

$53 \mathrm{wt} \%$ of $\mathrm{SiO}_{2}$. Initial crystallinity of the lava, as represented by scoria and bombs ejected from the intracrater lava ponds, was 25 vol\% (see Fig. 7 and Table 5 of Plechov et al. 2015). Later on, during transport in lava tubes, open channels, and lava flows, progressive cooling and degassing caused additional increase in crystallinity up to $43 \mathrm{vol} \%$.

Initial water content in the erupted magma was $1.19 \pm$ $0.1 \mathrm{wt} \%$ (Plechov et al. 2015). Lava of the studied lobes was already strongly degassed, where the degassing occurred in the intracrater lava ponds and during transportation through the tubes and channels. Gas vesicles in already solidified pahoehoe lobes were up to $5 \mathrm{~cm}$ in diameter, and the largest were concentrated in the upper parts of the lobes under the glassy rind. Gas with temperature of $1030{ }^{\circ} \mathrm{C}$, sampled from the skylight of the major lava tube (most proximal to the Naboko vent at distance $300 \mathrm{~m}$ ), had the following composition (mol\%): $95.5 \mathrm{H}_{2} \mathrm{O}, 0.47 \mathrm{CO}_{2}, 2.01 \mathrm{SO}_{2}, 1.18 \mathrm{HCl}$, and $0.34 \mathrm{HF}$ (Chaplygin et al. 2016). Maximum temperatures of the molten interior of moving lava flows (both ' $a$ 'a and pahoehoe), measured with a K-type thermocouple at depths of several centimeters, were $1082^{\circ} \mathrm{C}$; maximum temperatures on the lava surfaces measured by FLIR ThermaCam SC6400 were $1069^{\circ} \mathrm{C}$ (Edwards et al. 2015).

\section{Methodology}

\section{Measurements of dynamics of lava flows}

The method of time-lapse photography was applied to propagating flow lobes (both ' $a$ 'a and pahoehoe) and to lava flowing in stable channels exiting lava tubes. The process of propagation was recorded with Brinno TLC100 time-lapse cameras with a resolution of $1280 \times 1024$ pixels and a field of view of $49.5^{\circ}$. The cameras were installed on tripods at distances several meters to hundreds of meters from frontal parts of the propagating lava flows and lava channels, with the line of sight perpendicular to the flow direction. The cameras operated for time periods lasting from several hours to days with frame intervals ranging from $5 \mathrm{~s}$ to $1 \mathrm{~min}$, depending on the lava velocity. A meterstick or a person of known height was temporary placed in front of the lava flows or near the lava channel allow scaling of the images.

Time-lapse video clips (with rates of 10 frames/s) were processed with the Logger Pro software. Using this software, positions of flow fronts, lava levels/thicknesses, and positions of prominent rock fragments on the upper surface of the flows were manually traced in the image sequences, and their displacement and velocity was 

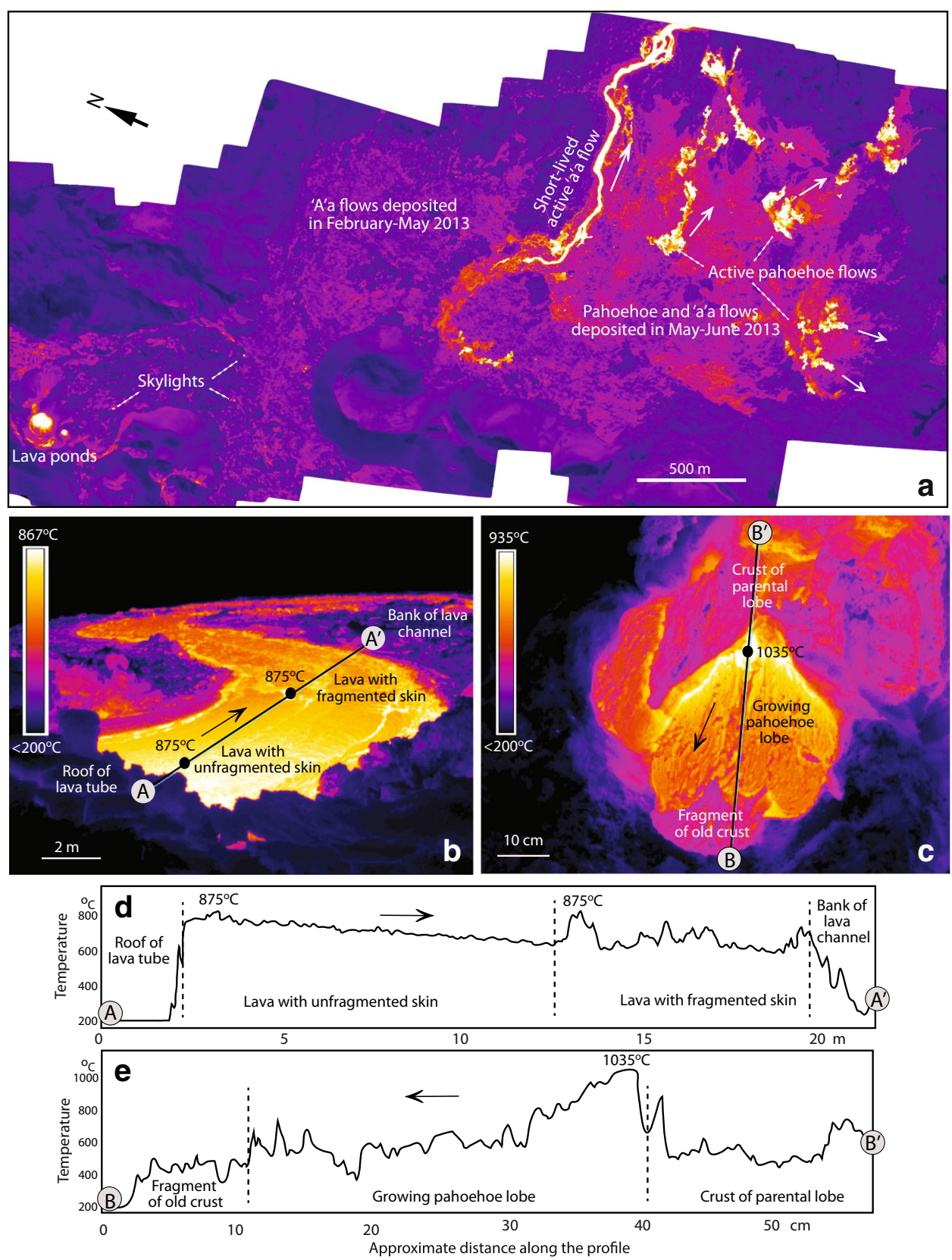

Fig. 4 FLIR images and temperature profiles of active lava flows of the 2013 eruption of Tolbachik volcano, courtesy by S. Chirkov and I. Dubrovskaya. a Mosaic of aerial images of Toludskoye lava field; 5 June. From lava ponds in the craters of the Naboko scoria cone (two oval bright spots in the left lower corner of the mosaic), lava is transported underground through a system of tubes marked by the skylights (only the largest are indicated), and then is emplaced on the ground surface as pahoehoe flows (indicated by the several irregular bright spots in the right part of the mosaic) that propagate over previously deposited 'a'a and pahoehoe flows (light purple area in the right part of the mosaic). A short-lived active 'a'a flow (long bright meandering band in the mid-upper part of the mosaic) has just formed due to rupture of the lava tube system. The large scoria cones visible around the lava field are prehistoric. b Image of a lava river exiting the tube outlet and flowing in open channel on March 19 (photo of the same flow is shown on Fig. 3a). Maximum temperature of lava in the tube outlet was $1055^{\circ} \mathrm{C}$. c Image of an actively growing pahoehoe lobe (with rear growth mode) on March 25. d Temperature profile along line
$\mathrm{A}-\mathrm{A}^{\prime}$ of image $\mathbf{b}$. Temperature steadily decreases over the first meters from the tube outlet (left part of the plot) where an upper viscous layer of the 'a' a flow starts to form. Farther down flow (right part of the plot), the temperature profile has spikes which correspond to hot and fluid lava of lower layer exposed in ruptures of the upper layer. These ruptures indicate the initiation of lava autobrecciation. e Temperature profile along the line B-B' of image c. The temperature of approximately $500{ }^{\circ} \mathrm{C}$ in the right part of the plot corresponds to the surface of a stagnated parental lobe. Max surface temperature of $1035^{\circ} \mathrm{C}$ corresponds to the spreading structure where the new skin of the growing lobe forms. With distance from the spreading structure, temperature steadily decreases while the lobe skin is getting older (temperature spikes correspond to grooves on the lobe surface). The left part of the plot, with $T=500{ }^{\circ} \mathrm{C}$ corresponds to the fragment of the old crust separated from the parental lobe attached to the new skin of the growing lobe. The temperature cutoff at $200{ }^{\circ} \mathrm{C}$ corresponds to snow surface which is bulldozed by the growing lobe. Scales and distances of the profiles are approximate. Arrows indicate the flow directions 
calculated. Using data of flow front velocities, flow surface velocities at different distances from the flow front, as well as temporal variations of the flow thicknesses and heights of lateral levees, were thus derived. For the lava channels, records of flow level and velocity fluctuations were also obtained.

Several additional time-lapse cameras were installed on high points surrounding the growing Toludskoye lava flow field to obtain an overall panoramic view. These cameras, working during time periods of up to 2 months with frame intervals of up to $30 \mathrm{~min}$, documented the general longterm evolution of the lava flow field morphology.

\section{Measurements of viscosity of lava flows}

\section{Flow rate method}

The flow rate method was applied mostly to 'a'a lava lobes as well as to two small pahoehoe lobes. The flow thickness and flow velocity data (measured with the Logger Pro software on the time-lapse video clips) were used to calculate apparent viscosities of the lava flows using Jeffreys' equations:

$\eta=\rho g h^{2} \sin \alpha / 3 V$

$\eta=\rho g h^{2} \sin \alpha / 2 V$

where $\eta$ is the viscosity of lava ( $\mathrm{Pa} \mathrm{s}), \rho$ is the bulk density ( $\mathrm{kg}$ / $\left.\mathrm{m}^{3}\right), g$ is the gravitational acceleration $\left(9.8 \mathrm{~m} / \mathrm{s}^{2}\right), h$ is the thickness of the lava flow (m), $\alpha$ is the surface slope (degrees), and $V$ is the velocity of lava flow $(\mathrm{m} / \mathrm{s})$. Equation (1) was used with data for the flow front velocity, and the Eq. (2) was used for velocities of the surface behind the flow front (Nichols 1939; Gauthier 1973; Panov et al. 1988).

For the 'a' a lobes, flow thicknesses and velocities were measured synchronously and in the same area of the flow (because both values changed with time). The measured thicknesses included the upper and basal breccias of the flows; hence, the obtained values of lava viscosity are probably slightly overestimated. The slope angles were measured in the field with an inclinometer. The average lava density was taken as $2500 \mathrm{~kg} / \mathrm{m}^{3}$, a value adopted from Andreev et al. (1978) who completed multiple density measurements of compositionally and texturally similar lavas of the Southern Breakthrough of the 1975-1976 eruption of Tolbachik.

\section{Shear stress method (penetration method)}

The shear stress method was applied to pahoehoe flows. Viscosity was measured by a custom-built penetrometer. A steel rod (a round bar with a half-spherical penetration head) was manually pushed into the active pahoehoe lobes with constant force (Fig. 3e; Online Resource Video ESM 2). In cases where the probed lobe was covered by a rigid crust, the rod was pushed into the lava through a small hole opened in the crust with a hammer. The force of penetration was controlled manually with a handheld spring balance. The force applied to the rod varied from 4 to $10 \mathrm{~kg}$ depending on the lava viscosity in each particular case, with $10 \mathrm{~kg}$ being the most commonly applied force (here recalculated from Newton units, N). The force was experimentally selected to obtain a total penetration time of a few seconds through a $10-25-\mathrm{cm}$ thick pahoehoe lobe. Three rods with differing dimensions and weights were used during different measurement campaigns (the rod parameters are listed in Table 2). The penetrating part of the rod had clearly visible length marks separated by $100 \mathrm{~mm}$ intervals. The process of penetration was filmed by conventional HDV video camera with the line of sight perpendicular to the direction of penetration, where the goal was to document the velocity of penetration apparent using the length marks on the rod. Each measurement continued until penetration into the lava lobe ceased. In most cases, the rod was pushed into the lava lobe perpendicular to its outer surface. In several cases, the rod was pushed horizontally under the lava crust to measure viscosity not influenced by lava depth. Each studied lava lobe and/or nearby lobe was repeatedly penetrated in order to check reproducibility of the measurements.

The video clips of the penetration process were processed with the Logger Pro software. The distances between the length marks on the penetrator rod provided a scale for the images. Positions of the marks on the rod were manually traced in each frame and their displacements and penetration velocities were calculated by the software. Viscosity was then calculated based on the Stoke's law. We used the equation for a half of a sphere (that is the half-spherical penetrating tip of the penetrator rod) as suggested by Panov et al. (1988):

$\eta=F / 3 \pi V R$

where $\eta$ is the viscosity of lava flow (Pa s), $F$ is the force of penetration $(\mathrm{N}), V$ is the velocity of penetration $(\mathrm{m} / \mathrm{s})$, and $R$ is the radius of penetration head (m). In Eq. (3), the total force of penetration was calculated as the external force applied to the rod (determined using the spring balance) plus the weight of the rod for cases where the direction of penetration was vertical. For cases of nonvertical penetration, the contribution of the rod weight to the total force of penetration was corrected using the angle of penetration through application of superposition principles. Changes in the penetration velocity with depth provided data that allowed us to calculate changes in viscosity throughout the entire lava lobe thickness (commonly to depths $10-25 \mathrm{~cm}$ ). 


\section{Lava flow dynamics}

\section{Dynamics of 'a'a flows}

The dynamics of seven active 'a'a flows were studied with time-lapse cameras in the period from March to April 2013 (Table 1). The 'a' a lobes propagated over rather smooth slopes having inclinations of up to $12^{\circ}$ (Fig. 2b). Individual flow lobes were 1-6 m thick, $10-50 \mathrm{~m}$ wide, and up to $1 \mathrm{~km}$ long (Fig. 3b, d; Online Resource Video ESM 3). The lobes were enveloped in loose clinker (lava autobreccia). Clinker fragments were commonly $5-20 \mathrm{~cm}$ and up to $50 \mathrm{~cm}$ across; some boulders composed of agglutinated clinker were up to $2 \mathrm{~m}$ in diameter. The upper surface of each active 'a'a flow lobe comprised a continuous, rather flat blanket of clinker (although commonly with a bulging-upward axial area and notable undulations down flow) slowly moving between steep lateral levees composed of the same stagnated material. Lateral levees bounding the active flow body had approximately the same heights as the moving flow surface between them. On the flow surface, clinker was relatively cold $(T<$ $\left.500{ }^{\circ} \mathrm{C}\right)$ and friable, while at depth, it was incandescent $(T=$ $600-900{ }^{\circ} \mathrm{C}$ as measured by FLIR). Internal parts of the 'a'a flow lobes were exposed in the flow snouts. Here, incandescent, highly viscous, cohesive lava breccia continuously extruded forward, forming blocks protruding from the frontal scree of clinker. These blocks commonly formed vertical cliffs indicative of the high yield strength. This material had limited ability for plastic deformation and under gravity tended to crumble into pieces. The flow snouts were composed of a moving scree of loose autobrecciated lava. Fluid lava was seldom exposed at the outer surfaces of the 'a'a flow lobes. In a few observed cases, it was squeezed through the scree of flow snouts or lateral levees to form short secondary pahoehoe flows (Fig. 3d).

The 'a'a flow lobes propagated in the classic style commonly called "caterpillar-track" motion (Rowland and Walker 1987), where maximum velocities of the frontal snouts were in the range $2-25 \mathrm{~mm} / \mathrm{s}$. Maximum velocities on upper surfaces of the flow bodies (measured simultaneously at distances tens to hundreds of meters behind the flows snouts) were commonly 1.5-3 times higher (Fig. 5, Table 1). The flow snouts propagated more slowly because a notable part of the advancing material within the frontal parts of the flows (mostly represented by lava breccia) was continuously dispatched to construction of both the flow's lateral levees and basal breccia. Because of the surface-snout velocity difference, clinker covering the surface was continuously carried by the flow toward its snout, where it periodically avalanched down the flow front.

The motion of each 'a'a flow was very unsteady. Both the snout and surface velocities experienced significant accelerations (surges), during which velocities increased by a factor of
2 or 3 , alternating with decelerations on time scales of the order of tens of minutes, even when the lava flows moved along smooth, obstacle-free surfaces (Fig. 5). These velocity fluctuations were observed in both actively advancing lobes and lobes in the final stages of propagation.

Video observations of the upper 'a'a flow surfaces (of the "flow body" located tens-hundreds of meters behind the flow snouts) revealed that there was no detectable velocity gradient across the flow (i.e., between the axial part of the flow surface and areas immediately adjacent to the lateral levees). Instead, the flow surface moved as a coherent plug. Simultaneous measurements of flow surface velocities at several points, scattered along the flow at distances of tens to hundreds of meters apart, revealed the complex nature of the plug motion. The flow surface consisted of segments (each tens of meters long) that experienced nonsynchronized periodic accelerations and decelerations. These accelerations and decelerations were generally not synchronized with accelerations and decelerations of the flow snout (Fig. 5). Only when a plug segment approached the frontal part of the flow, its average velocity begins to decrease to approach the velocity value of the flow snout. In this way, short-term accelerations and decelerations of a segment would gradually become synchronized with accelerations and decelerations of the flow snout. Differences in velocities of neighboring segments led to mechanical interactions between them as was evident from the changes of the local flow thickness: where a segment experienced compression, its thickness slightly increased and vice versa.

Marginal levees formed in the frontal area of an advancing flow lobe by two simultaneous processes: one operating at the lateral margins of the frontal area and another at the foot of the flow snout. When material of the flow approached its frontal area (approximately 10 to $20 \mathrm{~m}$ behind the flow snout where lateral levees were not yet formed and thus did not buttress against the moving part of the flow), its lateral parts started to gradually spread sideways under the force of gravity, where they thinned and decelerated (Online Resource Video ESM 3). At some threshold, their material, composed mostly of loose or weakly cohesive lava autobreccia, stagnated, progressively adding to the previously formed lateral levees of the body of the flow. Simultaneously, the axial part of the flow reached the steep slope of the flow snout. Here, cohesive lava breccia composing the flow continuously extruded forward, crumbled into pieces, and avalanched down to collect at the snout base. While part of the avalanched material was covered by the advancing flow to form a basal breccia, other parts were bulldozed in front of the flow snout. In the process of bulldozing, while some of the clasts of the breccia were rolled along, others agglutinated together to form accretionary balls 0.5-2 $\mathrm{m}$ across. Bulldozed debris, containing accretionary balls, from time to time was pushed aside by the advancing flow to form the lateral levees. The newly formed levees were notably lower than the upper surface of the flow body. Later, 
Table 1 Apparent viscosity of the 'a'a and pahoehoe lava flows of the 2013 eruption of Tolbachik measured by the flow rate method. Date (day/month) when the measurement was completed (also corresponds to the point number on Fig. 2b)

\begin{tabular}{|c|c|c|c|c|c|c|c|c|}
\hline Point (date) & Coordinates & $D, \mathrm{~km}$ & Flow part & $V, \mathrm{~m} / \mathrm{s}$ & $\alpha,{ }^{\circ}$ & $H, \mathrm{~m}$ & $\eta, \mathrm{Pa} \mathrm{s}$ & Comments \\
\hline \multicolumn{9}{|c|}{ A'a lava flows } \\
\hline \multirow[t]{3}{*}{1803} & \multirow[t]{3}{*}{$\begin{array}{l}55^{\circ} 45^{\prime} 06.7^{\prime \prime} \\
160^{\circ} 20^{\prime} 22.8^{\prime \prime}\end{array}$} & \multirow[t]{3}{*}{2.1} & $\begin{array}{l}\text { Front } \\
\text { Surface }\end{array}$ & $\begin{array}{l}0.004 \\
0.006\end{array}$ & 1 & 3 & $\begin{array}{l}3.8 \times 10^{5} \\
3.8 \times 10^{5}\end{array}$ & \multirow[t]{3}{*}{ Steady } \\
\hline & & & Front & 0.003 & 0.5 & 3.7 & $3.4 \times 10^{5}$ & \\
\hline & & & Surface & 0.0056 & & 3.6 & $2.7 \times 10^{5}$ & \\
\hline 1903 & $\begin{array}{l}55^{\circ} 45^{\prime} 02.5^{\prime \prime} \\
160^{\circ} 20^{\prime} 36.1^{\prime \prime}\end{array}$ & 2.4 & $\begin{array}{l}\text { Front } \\
\text { Surface }\end{array}$ & $\begin{array}{l}0.008 \\
0.018\end{array}$ & 8 & 3.5 & $\begin{array}{l}1.8 \times 10^{6} \\
1.2 \times 10^{6}\end{array}$ & Decelerating \\
\hline \multirow[t]{4}{*}{$304 a$} & \multirow{4}{*}{$\begin{array}{l}55^{\circ} 44^{\prime} 54.7^{\prime \prime} \\
160^{\circ} 21^{\prime} 04.6^{\prime \prime}\end{array}$} & \multirow[t]{4}{*}{2.9} & \multirow[t]{2}{*}{ Front } & 0.002 & \multirow[t]{4}{*}{6} & 5.5 & $1.3 \times 10^{7}$ & Steady \\
\hline & & & & $\begin{array}{l}0.0033 \\
0.0053\end{array}$ & & $\begin{array}{l}6.3 \\
5.4\end{array}$ & $\begin{array}{l}9 \times 10^{6} \\
4.5 \times 10^{6}\end{array}$ & Accelerating \\
\hline & & & \multirow[t]{2}{*}{ Surface } & 0.0027 & & 5 & $1.2 \times 10^{7}$ & Steady \\
\hline & & & & $\begin{array}{l}0.005 \\
0.007\end{array}$ & & $\begin{array}{l}5.6 \\
6.5\end{array}$ & $\begin{array}{l}8 \times 10^{6} \\
7.5 \times 10^{6}\end{array}$ & Accelerating \\
\hline \multirow[t]{2}{*}{$304 b$} & & & Front & $\begin{array}{l}0.0033 \\
0.0007\end{array}$ & 3 & $\begin{array}{l}1.8 \\
1\end{array}$ & $\begin{array}{l}4 \times 10^{5} \\
6.3 \times 10^{5}\end{array}$ & \multirow[t]{2}{*}{ Stopping } \\
\hline & & & Surface & 0.0053 & & 1 & $1.3 \times 10^{5}$ & \\
\hline \multirow[t]{3}{*}{$504 a$} & $\begin{array}{l}55^{\circ} 44^{\prime} 50.3^{\prime \prime} \\
160^{\circ} 21^{\prime} 33.5^{\prime \prime}\end{array}$ & 3.4 & Front & $\begin{array}{l}0.015 \\
0.016\end{array}$ & 12 & $\begin{array}{l}4 \\
3.5\end{array}$ & $\begin{array}{l}1.9 \times 10^{6} \\
1.3 \times 10^{6}\end{array}$ & \multirow[t]{3}{*}{ Steady } \\
\hline & & & & 0.025 & 10 & 3.6 & $7 \times 10^{5}$ & \\
\hline & & & Surface & 0.057 & & 2.7 & $3.3 \times 10^{5}$ & \\
\hline \multirow[t]{2}{*}{$504 \mathrm{~b}$} & & & $\begin{array}{l}\text { Front } \\
\text { Surface }\end{array}$ & $\begin{array}{l}0.008 \\
0.015\end{array}$ & 12 & $\begin{array}{l}2.8 \\
3\end{array}$ & $\begin{array}{l}1.7 \times 10^{6} \\
1.5 \times 10^{6}\end{array}$ & \multirow[t]{2}{*}{ Decelerating } \\
\hline & & & & 0.0033 & & 1.7 & $2 \times 10^{6}$ & \\
\hline \multicolumn{2}{|l|}{$504 \mathrm{c}$} & & Front & 0.0003 & & $\begin{array}{l}2.9 \\
2.4\end{array}$ & $\begin{array}{l}5 \times 10^{7} \\
3.3 \times 10^{7}\end{array}$ & Stopping \\
\hline \multicolumn{9}{|c|}{ Pahoehoe lava flows } \\
\hline 2007 & $\begin{array}{l}55^{\circ} 43^{\prime} 52.9^{\prime \prime} \\
160^{\circ} 20^{\prime} 39.8^{\prime \prime}\end{array}$ & 4.3 & front & 0.0024 & 80 & 0.1 & $3.5 \times 10^{4}$ & \multirow[t]{2}{*}{ Small subvertical "lava drop" } \\
\hline 2507 & $\begin{array}{l}55^{\circ} 43^{\prime} 40.9^{\prime \prime} \\
160^{\circ} 20^{\prime} 35.2^{\prime \prime}\end{array}$ & 4.6 & & 0.006 & & 0.13 & $2.4 \times 10^{4}$ & \\
\hline
\end{tabular}

$D$, distance from the source (the Naboko scoria cone); $V$, flow velocity; $\alpha$, angle of slope; $H$, flow thickness; $\eta$, calculated apparent viscosity (see the section "Methodology" for the calculation details); Comments, visual characteristics of the flow

the levees periodically grew in height and width, being built up by spillovers of clinker from the surface of passing flow body, as well by being moved aside, that is pushed or bulldozed outward to make the flow lobe broader. Both clinker spillovers and episodes of levee outward migration occurred during surges in the flow surface velocity, when the thickness of the flow body increased. As a result of these construction episodes at considerable distances from the flow front, the levee heights became almost equal to the thickness of the flow moving between the levees.

\section{Dynamics of pahoehoe flows}

The dynamics of 25 active pahoehoe flow lobes were studied with time-lapse cameras during three periods in March-April, May, and July 2013 (Table 1, Online Resource Video ESM 5). The pahoehoe flows advanced as multiple small (of the order of 0.3-2 $\mathrm{m}$, some up to $5 \mathrm{~m}$ long) bulbous lobes that extruded from numerous isolated points scattered along a flow front several tens to hundreds meters wide (Figs. 3c-e and 6). Maximum propagation velocity of individual flow lobes was from 0.5 to $6 \mathrm{~mm} / \mathrm{s}$ (Fig. 7a, b; Table 1). Individual lobes were not always extruded in the same direction. In many cases, the next lobe extruded perpendicular to, or even backward in relation to the extrusion direction of the parental lobe. As a result, the average propagation velocity of the entire pahoehoe front was slower than the velocity of individual lobes being around $1-2 \mathrm{~mm} / \mathrm{s}$ (Fig. $7 \mathrm{c}$ ).

Plots of growth rates (velocities of front motion through time) of individual lobes of simple morphology had a characteristic shape (Fig. 7a, b). Commonly, the maximum rate of lobe growth occurred in the initial phase or quickly accelerated to a maximal value during the first several minutes, and then exponentially slowed down. While the velocity of a 

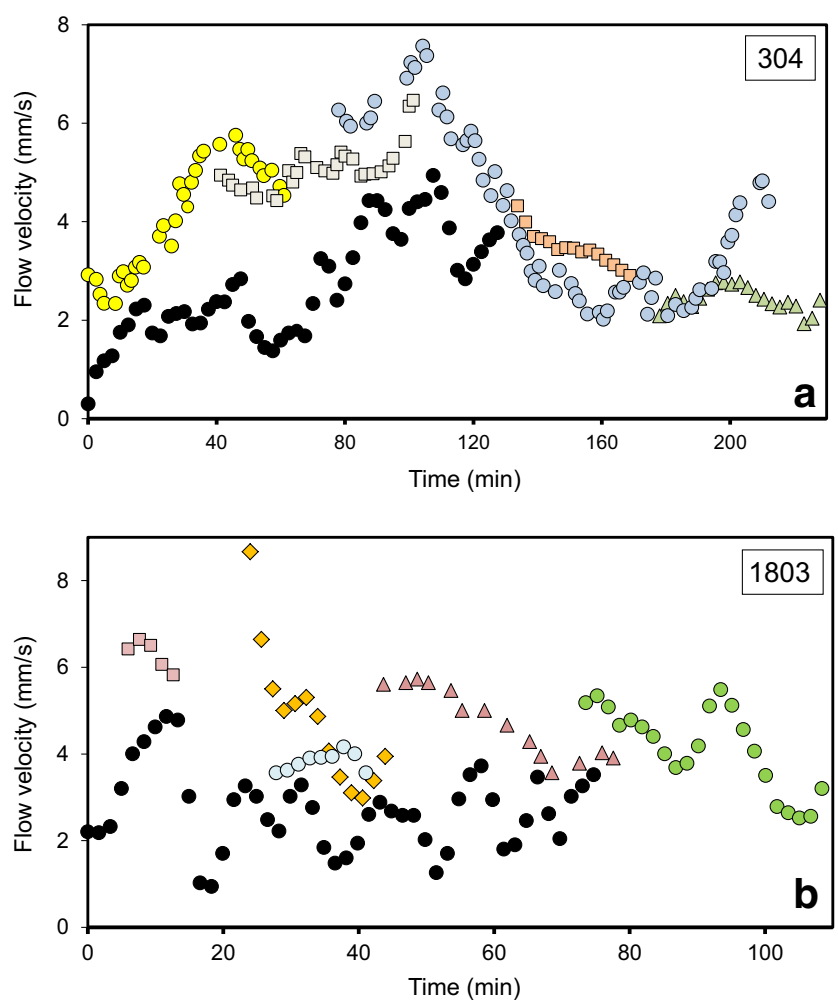

Fig. 5 Changes of the front and surface velocities of the 'a'a lava lobes of the 2013 eruption registered by time-lapse cameras. a Lava flow on April 3 at point 304 on Fig. 2b. b Lava flow on March 18 at point 1803 on Fig. $2 \mathrm{~b}$; see the same flow on the Online Resource Video ESM 3. Each symbol corresponds to a distinctive point on the surface of the flow (light-colored symbols), or the flow front (black circles), the position of which was manually traced from image to image of the time-lapse footage, and shows lateral velocity of this point calculated by the Logger Pro software (see details in the section "Methodology"). Some points are missing on the plots because at the corresponding pictures the lava flow is obscured by clouds of steam. Horizontal axis indicates the time elapsed since the beginning of the time-lapse footage. Surface velocities were measured at distances up to several hundred meters behind the flow front. The plot of the front velocity comes to end when the flow front travels beyond the video frame; plots of the surface velocities start/stop when the corresponding traced points on the flow surface start/stop to be visible

lobe's front motion decreased, the thickness of both the parental and the growing lobe started to increase progressively, indicating pressurization of the lobe interior, and the lobes inflated to obtain more equidimensional shapes. Deceleration of the lobe growth was accompanied by a decrease of its surface temperature that made the lobe skin more viscous. At some point, the lobe skin became too viscous to stretch (to accommodate inflation of the lobe under the continuing input of liquid lava), ruptured, and the next lobe started to grow, either from the opening fissure on the upper surface of the lobe crust or from the lobe base. The average lifetime of one lobe was of the order of 10 to $30 \mathrm{~min}$.

In most cases where the crust of the pahoehoe lobes ruptured, rather viscous lava slowly extruded from the opening fissure. Such lava quickly obtained a sturdy skin, so that the new lobe slowly inflated like a pressurized balloon of bulbous shape (Fig. 6). In some cases, less viscous lava broke out. Such lava initially had a thin, easily stretchable and flexible skin and formed small lava streams that commonly had a ropy surface. Low viscosity lava filling the interior of the parental lobe quickly drained out and left behind an empty shell of the solidified lobe crust. Such fluid lava streams were short-lived because the breakout areas were quickly self-sealed.

The shapes of individual lobes were different depending on their extrusion rates and the related skin viscosity. Slowly extruding equidimensional (sometimes nearly spherical) lobes with very viscous, almost solid skin were most common. Less common were rapidly growing lobes with a thin flexible skin. Their shape depended on substrate inclination; on lowgradient substrate, such lobes were flattened, but on steep slopes, they were elongated due to gravity. Lobes deposited in March-April had relatively rough surfaces in comparison with lobes deposited in May and June. That occurred because in March-April the pahoehoe lava was emplaced much closer to the source (the Naboko scoria cone) and was more vesicular. These vesicles, being stretched by the extrusion process, turned into linear groves and elongated cavities, similar to that of spiny pahoehoe of Peterson and Tilling (1980). The skin of most flow lobes was too viscous to form ropy surfaces. Ropy surfaces were characteristic for relatively rapid streams of fluid lava that from time to time broke through the front and upper surfaces of the growing lava flow field. If discharge of such breakout was sufficiently high, then it formed types of lava transitional from pahoehoe to 'a'a, including slabby pahoehoe.

Formation of pahoehoe lobes occurred by two modes, here termed "rear growth mode" and "frontal growth mode." In the first mode, formation and stretching of the new lava surface due to continuing inflation was concentrated along narrow spreading structures located at the rear of the lobe (Figs. 4c and 6a, b; Online Resources Video ESM 4 and Video ESM 5). In the second mode, formation of the new lava surface occurred on the basal surface of the lobe in close proximity to its front (Fig. 6c; Online Resources Video ESM 4 and Video ESM 6). Each mode produced lobes with specific surface patterns that were identifiable in the field (see details below).

In the case of the rear growth mode, extrusion of new lava commonly initiated from a fissure that slowly opened on the upper surface of the solidified crust of the previously emplaced lobe. In rare cases, extrusion started from the base of the parental lobe. The opening fissure was curved, and a polygonal segment of the old and thick crust, bounded by the fissure, slowly opened like a trap door. In some cases, it separated from the parental lobe and moved away attached to the stretching skin of the new lobe. During the rear growth mode, the formation of the lobe skin occurred along a narrow spreading structure commonly located along the boundary between the thick rigid crust of the parental lobe (sometimes under its 

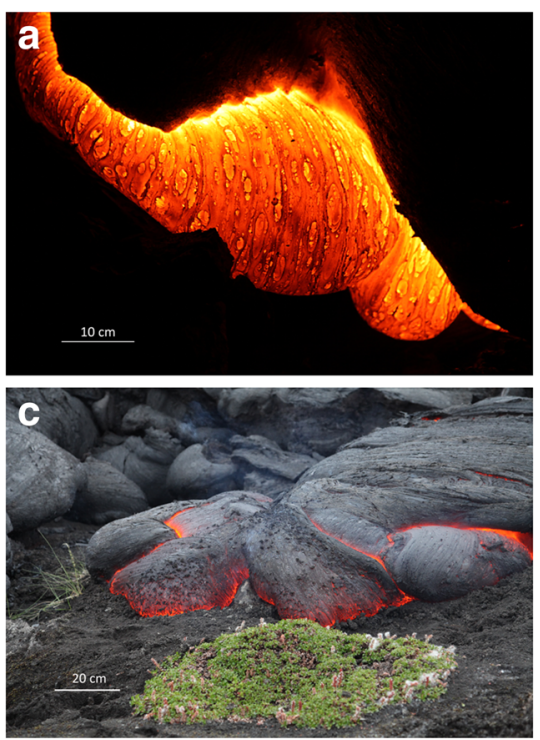

Fig. 6 The morphology of the active pahoehoe lobes of the 2013 eruption of Tolbachik. a The initial stage of formation of two lobes with the rear growth mode; night time view on July 16 . The hottest lava is in the rear parts of the lobes. b A mature lobe with rear growth mode on July 23. Large longitudinal groove along the axial part of the lobe surface was harrowed by the irregularity of the fissure through which lava extrudes (see video of the same lobe on Online Resource Video ESM 5). $\mathbf{c}$ Two lobes with frontal growth mode (center) on July 25 . The hottest lava is in

overhanging edge) and the younger, more flexible skin of the new lobe (Fig. 6a, b; Online Resources Video ESM 4 and Video ESM 5). The newly formed skin steadily moved away from the spreading structure and rolled over the lobe front, and the distance between the spreading structure and the lobe front gradually increased. While moving, the skin cooled, degassed, and thus gradually increased its viscosity and thickness with time. Thus, the youngest, hottest, thinnest, and most flexible part of the lobe surface was located near its rear part, and the oldest, coldest, thickest, and almost brittle near its front (Fig. $4 \mathrm{c}, \mathrm{e})$. When the surface of the growing lobe became too viscous to accommodate the inflation-related deformation, it fractured and the next lobe began to extrude from the opening fissure.

Lava lobes formed by the rear growth mode rarely grew as symmetrical bodies. Commonly, in the first few minutes after initiation of lobe extrusion, the process of formation and stretching of the new lava skin intensified on one side of the lobe. This side elongated faster than the others and the lobe obtained a curved, cashew-like shape (Online Resource Video ESM 4). The direction of bending depended on various (even subtle) external forces that influenced the lobe growth at the beginning of its extrusion. Lobes that started to extrude on a steep surface of the parental lobe commonly were bent downward by gravity; however, some lobes bent upward. Lobes that started to extrude onto a flat substrate were bent left or right depending on obstacles they collided with during the initial moments of lobe growth (e.g., neighboring lobes, or

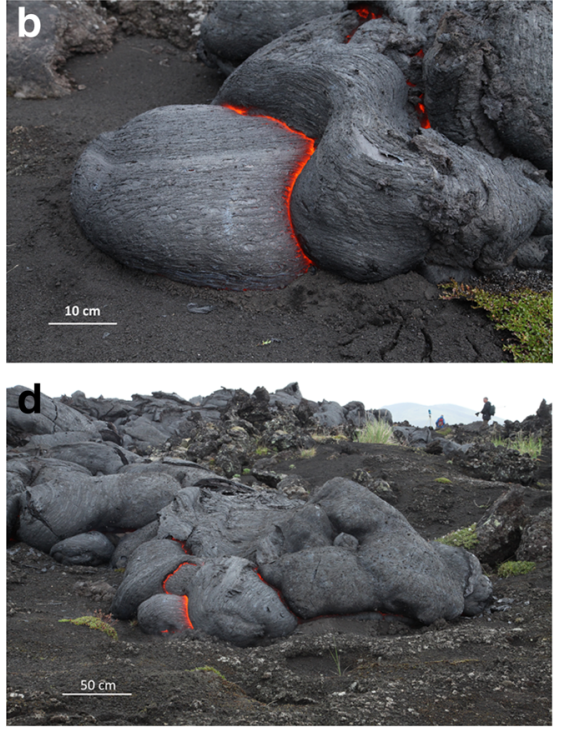

the frontal parts of the lobes. Particles of the substrate (scoria) are welded into the lobe's skin. The surrounding lobes are formed by rear growth mode. d Chain of lobes formed by both modes of growth on July 25 . Lobes formed by "rear growth mode" (left part of the image) have parallel longitudinal grooves; lobes formed by "frontal growth mode" (right part of the image) have rather smooth surfaces with welded-in particles of substrate (scoria). Photos by A. Belousov

irregularities in the substrate). Once the direction of bending was set, it had a propensity to persist, even if the growing lobe later met other obstacles. Some growing lobes were able to bulldoze snow or other loose substrates.

The upper surfaces of lobes that were formed by the rear growth mode had peculiar multiple parallel grooves aligned in the direction of the lobe extrusion (Fig. 6b). Most of the grooves were discontinuous and relatively shallow with depths of $<1 \mathrm{~cm}$ and originated from large gas vesicles strongly elongated in the direction of stretching of the lava skin (gas vesicles at the lobe surface are also elongated in the same direction). Longer continuous grooves with depths up to $5 \mathrm{~cm}$ were carved on the lobe surfaces by irregularities of the fracture through which lava extruded. Both types of grooves determined the direction of mechanical weakness of the lobe crust, and in many cases, when the next lobe started to extrude, the parental lobe fractured along one of these grooves. Multiple parallel grooves were diagnostic for lobes formed by the rear growth mode. The morphology of lobes formed by the rear growth mode was strikingly similar to the morphology of pillow lavas deposited in subaqueous conditions, although the latter propagate much faster (e.g., Ballard and Moore 2012). This can explain why the rear growth mode was dominant during winter time when cooling of lava surfaces was faster.

By summer time, the frontal growth mode became increasingly common, especially in locations where lava lobes advanced either over the hot surface of recently deposited lava, 
Fig. 7 Changes of the flow front velocities of pahoehoe lava flows of the 2013 eruption of Tolbachik documented by time-lapse cameras. Horizontal axis indicates the time elapsed since the beginning of the time-lapse footage. a, b Front velocities of the separate lobes sequentially extruded to form two lobe chains on July 25 (point 2507 on Fig.

$2 b)$. Photo of chain a is shown in Fig. 6d. Each symbol corresponds to an individual flow lobe. $\mathbf{c}$ Front velocity of the chain of lobes propagating through snow on April 8 (point 804 on Fig. 2b). The positions of the lobe fronts and of the lobe chain were manually traced from image to image of the time-lapse footages and show lateral velocities of the fronts calculated by the Logger Pro software (see details in the section "Methodology"). Some points are missing on the plots because at the corresponding pictures the lava flow is obscured by clouds of steam
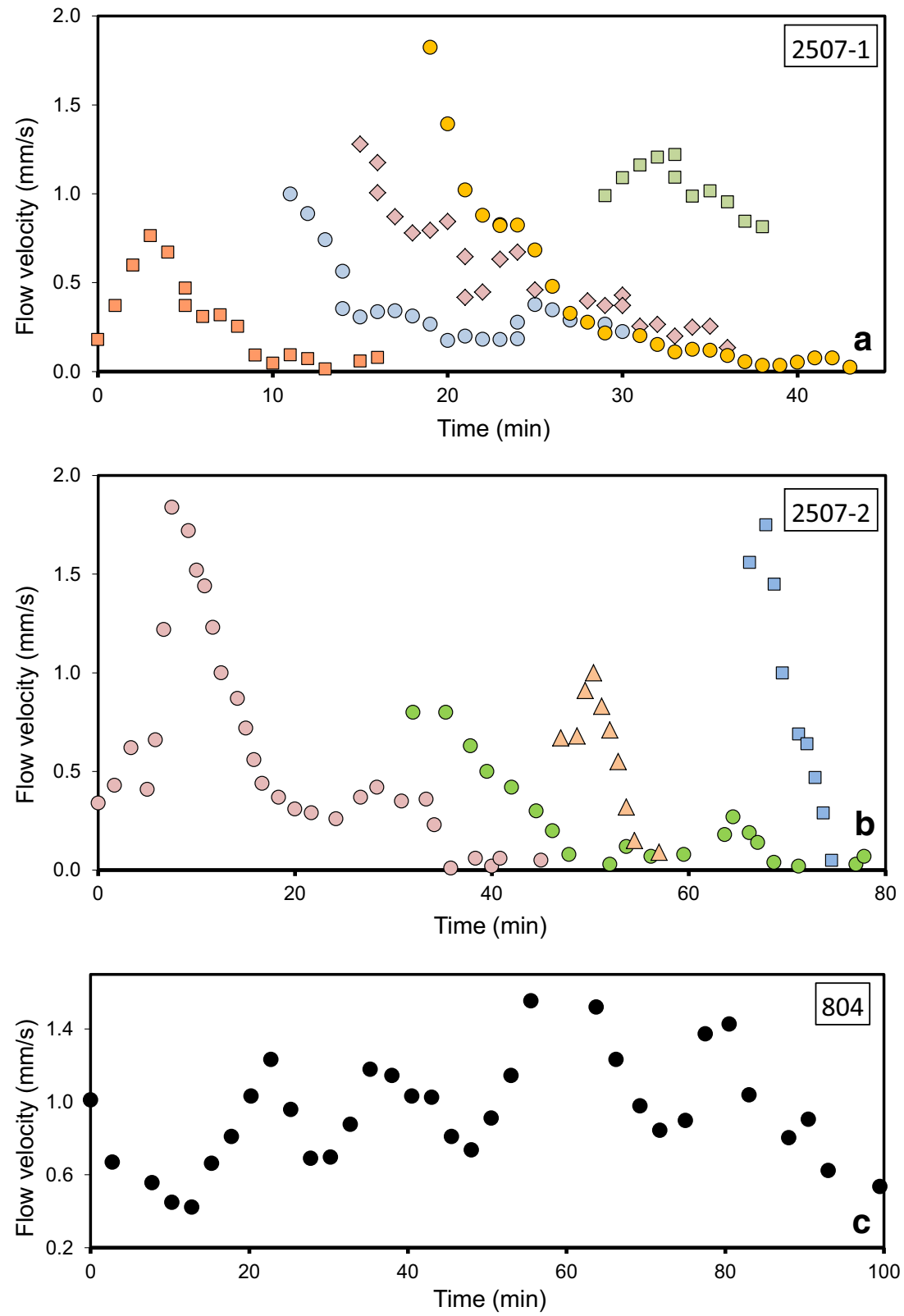

or over a substrate with good thermal insulation properties (e.g., dry scoria). However, there were many examples when both modes of lobe growth were observed either simultaneously in the same location (Online Resource Video ESM 4) or, during the process of formation of a lava lobe, one growth mode could switch to another. Lobes displaying the frontal growth mode commonly started to extrude not from fractures in the lava surface, but from under the basal contacts of parental lobes. In the case of frontal growth mode, the formation and stretching of new skin occurred on the basal surface of the lobe. Since we could not observe the base, there is no data on how the stretching structure looked like and where on the base it was located. Probably, this structure was located on the basal surface in close proximity to the lobe front and aligned along it. In the process of lobe growth, the spreading structure steadily moved forward following the direction of flow front propagation. While the newly formed, incandescent, thin, and flexible skin slowly formed along the contact of the lobe front and the substrate, the front would simultaneously inflate and propagate forward (Fig. 6c; Online Resources Video ESM 4 and Video ESM 6). The resulting slow backward receding motion of the lobe surface (relative to the position of the lobe front) could be traced by the motion of particles of the substrate attached into the skin (e.g., fragments of old scoria or loose lava chips). Lava surfaces lacking parallel grooves and having embedded particles of substrate were diagnostic of lobes formed by the frontal growth mode (Fig. 6c, d). On steep substrates, the spreading 
structure of the surface migrated from the base to the snout of the lobe; such lobes obtained elongated shapes with smooth surfaces lacking the embedded substrate particles. In a few locations, numerous juxtaposed lobes of such morphology formed pahoehoe lava of the entrail type.

Sequentially, or nearly sequentially extruded lobes (irrespective of their growth modes and propagation directions) formed chains of hydraulically interconnected bulbous bodies up to $10 \mathrm{~m}$ long. Each chain contained one or several active lobes (in the last case growing at different rates). Such chains demonstrated a propagation with quasi-periodic accelerations-decelerations with a period of approximately 5$15 \mathrm{~min}$, even when they propagated along smooth obstaclefree surfaces (Fig. 7c). Most of the decelerations occurred during stagnation of the active lobes of the chain accompanied by the overall inflation of the chain and accumulation of lava inside it. The accelerations occurred during the following lava outbreaks and fast growth of new active lobes accompanied by the overall deflation of the chain. Some of the decelerations of the front occurred when the chain experienced "upstream" outbreaks of lava.

Emplacement of multiple juxtaposed lobe chains formed a broad, slowly propagating front of the pahoehoe lava field. Lobes composing the field contained fluid cores that continued to be hydraulically interconnected over long distances for many hours/days after the initial emplacement. From time to time, outbreaks of fluid lava locally depressurized the growing pahoehoe field. However, such outbreaks were quickly selfsealed.

Large areas of the pahoehoe field experienced one or several episodes of postemplacement secondary inflation, with extrusion of new lobes along lateral margins, as well as at different places across the upper surface of the lava flow field. Time-lapse footage of one of these areas (with an area of approximately $400 \mathrm{~m}^{2}$ ) showed that it inflated as a whole entity with a vertical rate of $0.03 \mathrm{~mm} / \mathrm{s}$. During the inflation process, one lateral margin of the inflating area produced flow lobes, while along the opposite margin, the inflation was accommodated by the slow opening of an inflation cleft structure (terminology after Walker 1991).

\section{Viscosity of lava}

\section{'A'a flows}

\section{The flow rate method}

The flow rate method was the main method used to measure the viscosity of the 'a'a flows. Measurements were completed during March-April 2013 when 'a'a flows were the dominant form of lava propagation and emplacement. Velocities of flow snouts, as well as velocities of the flow surfaces at distances up to several hundreds of meters behind the advancing snouts, were used for the viscosity calculations because in these locations the flow thickness over the underlying substrate was easy to determine (assuming no erosion and/or breccia accumulation at the flow base). Both frontal and surface velocities fluctuated with time (Fig. 5), so for each particular flow, only maximum velocity values were used for the calculations (Fig. 8, Table 1). Calculations based on the frontal and surface velocities provided similar viscosity values $\left(1.3 \times 10^{5}-3.3 \times\right.$ $\left.10^{7} \mathrm{~Pa} \mathrm{~s}\right)$. Material of the flow lobes had high yield strength. The height of the lateral levees $(2 \mathrm{~m})$ of the flow emplaced on March 19 allowed to estimate yield strength as $8600 \mathrm{~N} / \mathrm{m}^{2}$ (calculated by the equation 1 of Fink and Zimbelman 1983).

In most cases, the surface velocities of lava measured in open channels in locations proximal to the lava tube outlets could not be used for viscosity calculations because the thickness of the flowing lava was not known. An additional problem was the small slope angles in these areas, which were difficult to measure precisely with the inclinometer, where a small error in the measured angle causes a large error in the calculated apparent viscosity. However, in one case on April 4 , the lava channel thickness $(6.5 \mathrm{~m})$ was estimated based on the diameter of a spherical "lava boat" that rolled over the bottom of the lava-filled channel. The velocity of the lava in the channel was of $0.13 \mathrm{~m} / \mathrm{s}$. The calculated apparent viscosity ranged from $4 \times 10^{4}$ to $2 \times 10^{5} \mathrm{~Pa} \mathrm{~s}$ (depending on the assumed slope angle $0.5-3^{\circ}$ ), which is in between the apparent viscosities of the simultaneously emplaced 'a' a flow lobes and the viscosity of their secondary pahoehoe flows determined by the shear stress method (see below).

\section{The shear stress method}

We could not apply the shear stress method directly to 'a'a flow lobes because lava exposed at their surfaces was too viscous to use the penetrometer. However, on April 8, we used the penetrometer to measure the viscosity of secondary pahoehoe flows squeezed out of the 'a'a flows. Lava of these lobes represented the internal low-viscosity material of the 'a'a flows. It had a viscosity similar to that of other pahoehoe lobes of the eruption that were effused in May and July (0.6$3.3) \times 10^{4} \mathrm{~Pa} \mathrm{~s}$, and was one order of magnitude lower than the lowest values obtained by the flow rate method for the ' $a$ 'a flows emplaced on April $3\left(10^{5}-10^{6} \mathrm{~Pa} \mathrm{~s}\right)$ (Tables 1 and 2, Fig. 8).

\section{Pahoehoe}

\section{The shear stress method}

Only lobes with the rear growth mode were studied. These lobes were in different stages of formation: young, actively growing with thin and flexible outer skin; mature, slowly 


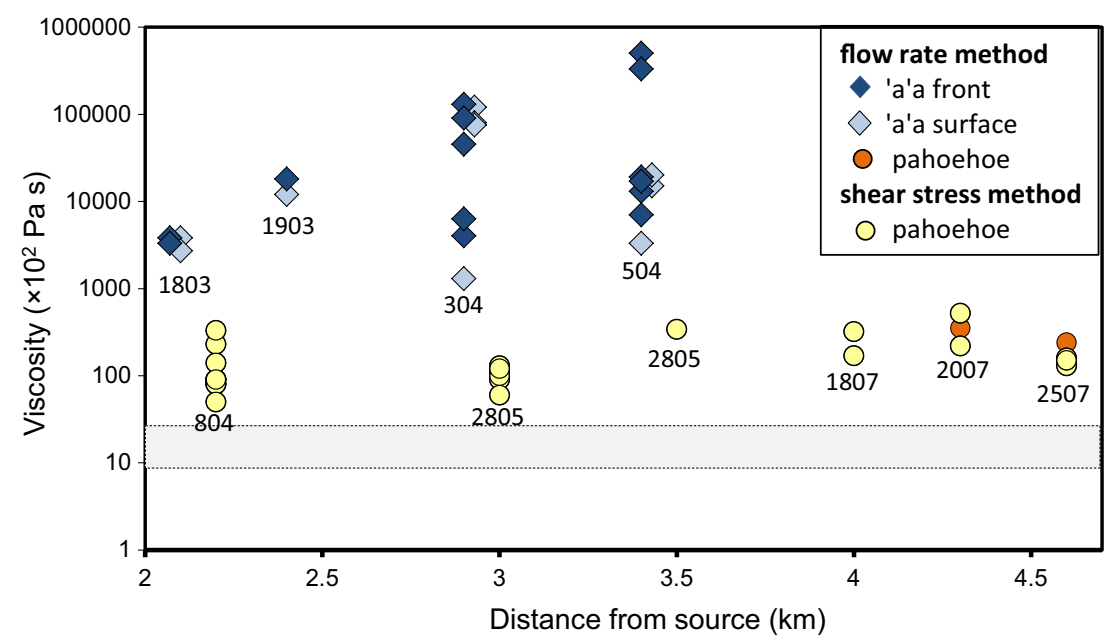

Fig. 8 Viscosities of the 'a'a and pahoehoe lava flows of the 2013 eruption of Tolbachik versus distance from the source (the Naboko scoria cone). Only the lowest values of viscosities measured by each method at each point are shown. Numbers indicate date and month of the measurements (also correspond to the point locations shown in Fig.

growing with thick and stiff skin; and already stagnated with solidified, rigid crust. In May, the penetration method was also applied to slowly flowing lava visible in a narrow, deep fissure in a thick crust covering a small lava channel.

The penetration process of lava commonly occurred in three stages: (1) the working end of the penetrometer caused the outer viscoelastic skin to sag downwards; (2) the working end then punctured the viscoelastic surface and started to plunge into the lava with rapidly increasing velocity that reached maximum values at depths of several centimeters; and (3) acceleration of the penetration changed to deceleration, as the basal more viscous layer was encountered, and at lava depths $15-25 \mathrm{~cm}$, the penetration practically ceased before the working end reached the base of the lobe. The velocity data for the penetration during stages 2 and 3 and Eq. (3) were used to calculate viscosity profiles through lava (Fig. 9, Table 2). Minimum viscosity values span the interval from $5 \times 10^{3}$ to $5 \times 10^{4} \mathrm{~Pa}$ s. Repeated penetrations of each lobe and/or neighboring lobes provided similar results, indicating good reproducibility of the measurements. Tests were also conducted with various forces of penetration. Not much difference in the calculated viscosities for the tests with forces of 30 and $127 \mathrm{~N}$ was found. From the deformation rates generated during our measurements (at penetration rates $<146 \mathrm{~mm}$ / s), we see that the lava behaved as a Newtonian liquid.

All the depth profiles obtained from vertical penetrations through the pahoehoe lobes had similar shapes (Fig. 9a, b). Relatively viscous lava composed a superficial layer $1-2 \mathrm{~cm}$ thick that comprised the lobe's skin. Below the skin, viscosity quickly decreased with depth and the most fluid lava was commonly located at depths of $2-5 \mathrm{~cm}$. After this, viscosity exponentially increased to values of approximately $10^{5} \mathrm{~Pa} \mathrm{~s}$ where the penetration practically stopped at depths of 10
$2 \mathrm{~b})$. The horizontal shaded band indicates the range of viscosities of the 2013 lavas calculated by Plechov et al. (2015) based on their temperature, mineral, and chemical composition following the method of Bottinga and Weill (1972)

$25 \mathrm{~cm}$ as it reached the highly viscous lava near the lobe base. The outer skin as well as the internal lava of actively growing lobes was several times less viscous than those of stagnated lobes being $(0.5-3.3) \times 10^{4}$ and $(3.2-42) \times 10^{4} \mathrm{~Pa} \mathrm{~s}$, respectively. Internal lava of stagnated lobes (residing under the rigid crust) was more homogeneous than the internal lava of active lobes, having almost no viscosity gradient with depth (Fig. $9 \mathrm{c})$. Horizontal penetrations provided viscosity values similar to those obtained by vertical penetrations; however, the viscosity profiles demonstrated relatively subtle changes with penetration distance (see measurement 1-97, point 804 in Table 2).

Flowing lava in narrow, deep fissures (measured on May 28; Fig. 9d) had viscosity values of $(0.6-1.3) \times$ $10^{4} \mathrm{~Pa}$ s. The shape of depth profile was similar to those obtained for the pahoehoe lobes. However, this lava had no prominent superficial viscous layer (i.e., there was no obvious viscoelastic skin on the flow surface). This was probably due to less effective air cooling of lava exposed in the deep fissure.

\section{The flow rate method}

We applied the flow rate method to only two pahoehoe lobes that were flowing down along a subvertical substrate and resembled large drops of lava. These lobes were short-lived, propagated relatively quickly (around $2-6 \mathrm{~mm} / \mathrm{s}$ ), and thus were enveloped in thin flexible skin that minimally affected the flow process. Only in these special cases the calculated apparent viscosity $\left(2.4 \times 10^{4}\right.$ and $\left.3.5 \times 10^{4} \mathrm{~Pa} \mathrm{~s}\right)$ turned out to be similar to viscosity values simultaneously obtained for internal parts of the nearby lobes by the shear stress method (Table 1, Fig. 8). 
Table 2 Viscosity of the pahoehoe lava of the 2013 eruption of Tolbachik measured by the shear stress method (with the penetrometer). Date (day/ month) when the measurement was completed (also corresponds to point number on Fig. 2b)

\begin{tabular}{|c|c|c|c|c|c|c|c|c|c|c|}
\hline $\begin{array}{l}\text { Point/ } \\
\text { date }\end{array}$ & $\begin{array}{l}\text { Measurement } \\
\text { number }\end{array}$ & Coordinates & $\begin{array}{l}D, \\
\mathrm{~km}\end{array}$ & $t, \mathrm{~s}$ & $\begin{array}{l}F \\
\mathrm{~N}\end{array}$ & $\alpha,{ }^{\circ}$ & $\begin{array}{l}\text { Rod } \\
\text { size }\end{array}$ & $V, \mathrm{~mm} / \mathrm{s}$ & $\eta, \times 10^{4} \mathrm{~Pa} \mathrm{~s}$ & Comments \\
\hline \multirow[t]{9}{*}{804} & $1-97$ & $55^{\circ} 45^{\prime}$ & \multirow[t]{9}{*}{2.2} & 6.3 & 120 & 21 & \multirow{9}{*}{$\begin{array}{l}0.014 \\
1.8 \\
3\end{array}$} & $9.4-41.6(20.8)$ & $2.3-10(4.5)$ & \multirow{9}{*}{$\begin{array}{l}\text { Lava under rigid crust } \\
\text { Fast growing lobe with soft skin }\end{array}$} \\
\hline & $1-98$ & & & 14.8 & 125 & 15 & & $0.4-29(10.7)$ & $3.3-240(9)$ & \\
\hline & $1-99$ & \multirow{7}{*}{$\begin{array}{r}160^{\circ} 20^{\prime} \\
40.6^{\prime \prime}\end{array}$} & & 15.9 & 30 & 90 & & $0.7-24.4(13)$ & $0.9-32.4(1.7)$ & \\
\hline & $1-100$ & & & 7.3 & & & & $8.3-25.7(15.6)$ & $0.9-2.7(1.4)$ & \\
\hline & $1-104$ & & & 7.8 & & & & $2.4-29.4(15.2)$ & $0.8-9.4(1.4)$ & \\
\hline & $1-105$ & & & 3.9 & 60 & 72 & & $10.8-34.3(22.5)$ & $1.4-4.3(2.0)$ & \\
\hline & $1-106$ & & & 5.2 & 85 & 56 & & $16.6-79.7(47)$ & $1.1-5.4(2.4)$ & \\
\hline & $1-107$ & & & 2.5 & 95 & 48 & & $10.8-77(50.3)$ & $0.9-6.8(1.5)$ & \\
\hline & $1-108$ & & & 5.6 & 105 & 39 & & $9-146.5(56.5)$ & $0.5-9(1.5)$ & \\
\hline \multirow[t]{6}{*}{$2805 \mathrm{a}$} & $2-305$ & $55^{\circ} 44^{\prime}$ & \multirow[t]{6}{*}{3} & 7.1 & 80 & 30 & 0.0125 & $1.4-78.1(36)$ & $0.9-5(1.9)$ & \multirow[t]{6}{*}{ Lava flowing in deep fissure } \\
\hline & $2-307$ & $24.8^{\prime \prime}$ & & 5.1 & 57 & 45 & 2 & $5.3-47.7(23)$ & $1.1-9.3(2.1)$ & \\
\hline & $2-308$ & \multirow{4}{*}{$\begin{array}{r}160^{\circ} 19^{\prime} \\
47.1^{\prime \prime}\end{array}$} & & 4.6 & 60 & 35 & \multirow[t]{8}{*}{3} & $4.2-39.4(20.8)$ & $1.3-12.4(2.5)$ & \\
\hline & $2-309$ & & & 4.2 & 65 & 20 & & $10.4-55.6(22.3)$ & $1-5.4(2.5)$ & \\
\hline & $2-311$ & & & 3.4 & 57 & 55 & & 4-41.7 (17.7) & $1.2-20(2.8)$ & \\
\hline & $2-312$ & & & 5.8 & 63 & 47 & & $2.7-94(36)$ & $0.6-5.6(2.0)$ & \\
\hline \multirow[t]{4}{*}{$2805 b$} & $2-17$ & $55^{\circ} 44^{\prime}$ & \multirow[t]{4}{*}{3.5} & \multirow[t]{4}{*}{15} & \multirow[t]{4}{*}{127} & \multirow[t]{4}{*}{7.5} & & $0.3-32.4(9)$ & $3.4-370(12.2)$ & \multirow[t]{4}{*}{ Stagnated lobe with rigid crust } \\
\hline & & $10.7^{\prime \prime}$ & & & & & & & & \\
\hline & & $160^{\circ} 19^{\prime}$ & & & & & & & & \\
\hline & & $59.8^{\prime \prime}$ & & & & & & & & \\
\hline \multirow[t]{4}{*}{1807} & $3-7820$ & $55^{\circ} 43^{\prime}$ & \multirow[t]{4}{*}{4} & 11.1 & 90 & 40 & \multirow{12}{*}{$\begin{array}{l}0.015 \\
1.5 \\
1,5\end{array}$} & $1.9-25.6(13)$ & $3.2-42(5.0)$ & \multirow[t]{4}{*}{ Stagnated lobe with rigid crust } \\
\hline & $3-7822$ & $59.3^{\prime \prime}$ & & 17.7 & 51 & 68 & & $0.3-38.4(11.4)$ & $1.7-220(5.7)$ & \\
\hline & & $160^{\circ} 20^{\prime}$ & & & & & & & & \\
\hline & & $29.8^{\prime \prime}$ & & & & & & & & \\
\hline \multirow[t]{4}{*}{2007} & $3-180$ & $55^{\circ} 43^{\prime}$ & \multirow[t]{4}{*}{4.3} & 8.9 & 113 & 8 & & $0.3-15.6(6.8)$ & $5.2-270(14.7)$ & \multirow{4}{*}{$\begin{array}{l}\text { Slowly spreading structure in rigid } \\
\text { crust }\end{array}$} \\
\hline & $3-184$ & $52.9^{\prime \prime}$ & & 10.8 & 113 & 4 & & $0.9-37.5(11.3)$ & $2.2-90(7.1)$ & \\
\hline & & $160^{\circ} 20^{\prime}$ & & & & & & & & \\
\hline & & $39.8^{\prime \prime}$ & & & & & & & & \\
\hline \multirow[t]{4}{*}{2507} & $3-130$ & $55^{\circ} 43^{\prime}$ & \multirow[t]{4}{*}{4.6} & 2.2 & 110 & 12 & & $10.4-63.5(30)$ & $1.3-7.8(2.7)$ & Fast growing lobe with soft skin \\
\hline & $3-132$ & $40.5^{\prime \prime}$ & & 3.5 & 113 & 2 & & $1.5-52.7(20)$ & $1.5-54(4.1)$ & \multirow{3}{*}{$\begin{array}{l}\text { Slowly growing lobe with stiff } \\
\text { skin }\end{array}$} \\
\hline & $3-132 \mathrm{a}$ & $160^{\circ} 20^{\prime}$ & & 7.6 & 113 & 3 & & $1.5-50.3(17.4)$ & $1.6-54(4.7)$ & \\
\hline & $3-133 a$ & $40.1^{\prime \prime}$ & & 8 & 113 & 6 & & $2.8-56.2(26)$ & $1.5-24(3.1)$ & \\
\hline
\end{tabular}

Measurement number, the number of the video file of the measurement; $D$, distance from the source (the Naboko scoria cone); $t$, penetration duration in seconds; $F$, total force of penetration in $\mathrm{N}$ (the force applied manually to the penetrating rod plus force posed by the rod's weight corrected for the penetration angle); $\alpha$, angle of penetration (from horizontal); Rod size: radius of penetrator head (m), length (m), and weight (kg); $V$, velocity of penetration (average value in parenthesis); $\eta$, calculated viscosity (average value in parenthesis); Comments, visual characteristics of the flow. See the section "Methodology" for the details of the viscosity calculation

\section{Discussion}

\section{Viscosity}

In our study, viscosities of the 'a'a flows were determined by the flow rate method, whereas viscosities of the pahoehoe flows were determined mostly by the shear stress method using the penetrometer. The flow rate method turned out to not be suitable for the majority of the pahoehoe lobes produced during the eruption. Due to surface cooling and degassing, the lobes quickly obtained a stiff viscous skin (see viscosity profiles in Fig. 9), which retarded the flow process. In most cases, pahoehoe lobes more closely resembled inflating balloons than fluid flows under the force of gravity.
In turn, the shear stress method was not suitable for the 'a' a lobes, because they were too viscous to be probed with our handheld penetrometer. Each method, if applied to the appropriate flow type, provided meaningful and reproducible viscosity data.

Viscosity values of the 2013 lavas obtained by both methods span the interval broadly comparable with published viscosity data for lavas of basic compositions worldwide (Fig. 1 and Online Resource Table ESM 1). The 'a' a lavas were more viscous than the pahoehoe lavas. Pahoehoe lavas produced in Hawaii (Nichols 1939; Macdonald 1953; Shaw et al. 1968) were more fluid than the studied pahoehoe lavas of Tolbachik. Viscosity values of the compositionally similar lavas of the 2013 and the 1975-1976 eruptions of Tolbachik 

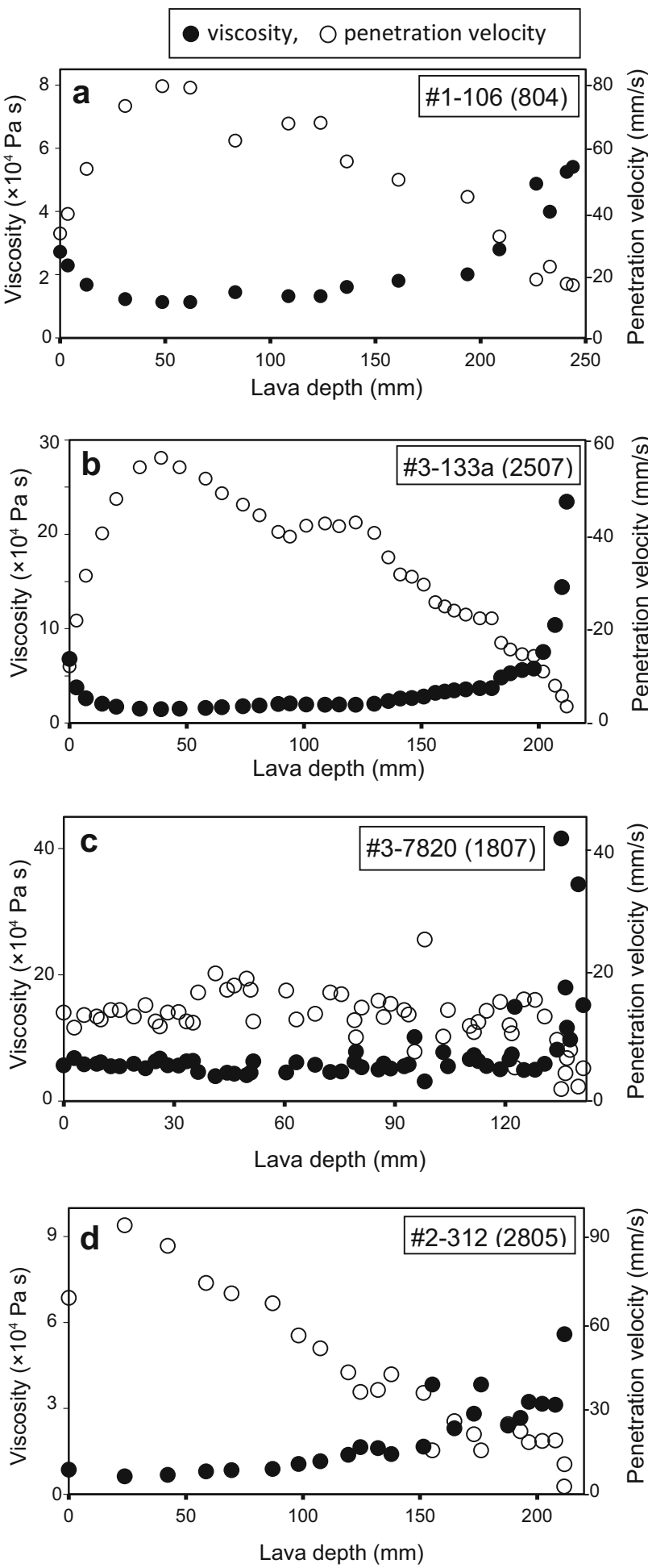

span similar intervals. Viscosities of the 2013 lavas calculated by the method of Bottinga and Weill (1972) based on their temperature and mineral and chemical composition are in the range (0.9-2.8) $\times 10^{3} \mathrm{~Pa}$ s by Plechov et al. (2015), in good agreement with our data $\left(6 \times 10^{3} \mathrm{~Pa} \mathrm{~s}\right)$ for the internal, most fluid parts of the pahoehoe lobes (Fig. 8).
Fig. 9 Examples of profiles of viscosity (and the corresponding penetration velocity) versus lava depth through active pahoehoe flows of the 2013 eruption. a A fast growing lobe with soft and flexible skin on April 8. b A slowly growing lobe with stiff skin on July 25. c A stagnated lobe on July 18. d A slowly flowing lava exposed in a deep fissure in the roof of a small lava tube on May 28. All the measured pahoehoe lobes formed by rear growth mode (see text for details). Relatively viscous lava in the left part of the plots corresponds to the lobe skin; the least viscous lava of the lobe rests directly below the skin; more viscous lava in the right part of the plot corresponds to the lobe base. Shape of viscosity profiles shown in $\mathbf{a}$ and $\mathbf{b}$ is characteristic for all the studied pahoehoe lobes of the eruption. Locations of the measurements are in Fig. $2 b$

Among the 2013 lavas, viscosities of the pahoehoe lobes are systematically about one order of magnitude lower than viscosities of the 'a'a lobes (Fig. 8). However, these data should not be interpreted as meaning that the 'a'a lobes were formed by lavas originally more viscous than those that fed the pahoehoe lobes. We applied the flow rate method only to distal 'a'a lobes where thicknesses of the lava flow could be easily measured. Lava exposed in the fronts of these lobes represented highly viscous cohesive autobreccia. Upstream, these lobes were fed by fast flowing streams of fluid lava that was too hot to approach for use of the penetrometer, and there were no data for flow thickness to allow application of the flow rate method. The only measurement completed by the flow rate method near the 'a'a-feeding lava bocca on April 4 provided the viscosity values of between $4 \times 10^{4}$ and $2 \times$ $10^{5} \mathrm{~Pa} \mathrm{~s}$, only slightly higher than viscosities of the pahoehoe flows of the eruption. Moreover, secondary pahoehoe flows that in April were squeezed out of the internal parts of the ' $a$ 'a lobes had viscosities of $(6-33) \times 10^{4} \mathrm{~Pa} \mathrm{~s}$, that is identical to the viscosities of the pahoehoe lavas emplaced in May and July. From these similarities, we conclude that the viscosity of the parental lavas for both ' $a$ 'a and pahoehoe lavas during 2013 eruption was the same. The differences in their viscosities resulted from processes, such as cooling, crystallization, and degassing, operated during transport of the lava down the distribution system, this mostly being in open channels for the ' $a$ 'a and in tubes for the pahoehoe.

\section{Change of dominant lava propagation style}

During March-July 2013, Tolbachik erupted lavas of constant chemical, mineralogical, and physical properties with a stable discharge rate. These lavas propagated over the same slopes (similar inclination, roughness, etc.) and were emplaced at similar distances from the volcano. Despite all that, the dominant style of lava propagation and emplacement changed with time from 'a'a to pahoehoe. We attribute this change to a gradual evolution of the lava transport system that fed the flow fronts throughout the course of the eruption. The transport system slowly evolved from one to two short and broad tubes, having few large branches with large outlets (Fig. 10a), to long 
Fig. 10 Schematic representations of the lava transport systems that formed Toludskoye lava flow field of the 2013 eruption of Tolbachik. a The lava transport system that fed the dominant 'a'a lava flows during the initial period of the lava field formation. b The lava transport system that fed the dominant pahoehoe lava flows during final period of the lava field formation. Thick arrows indicate the direction of the lava flows. The scale is approximate; widths of lava channels and tubes are exaggerated
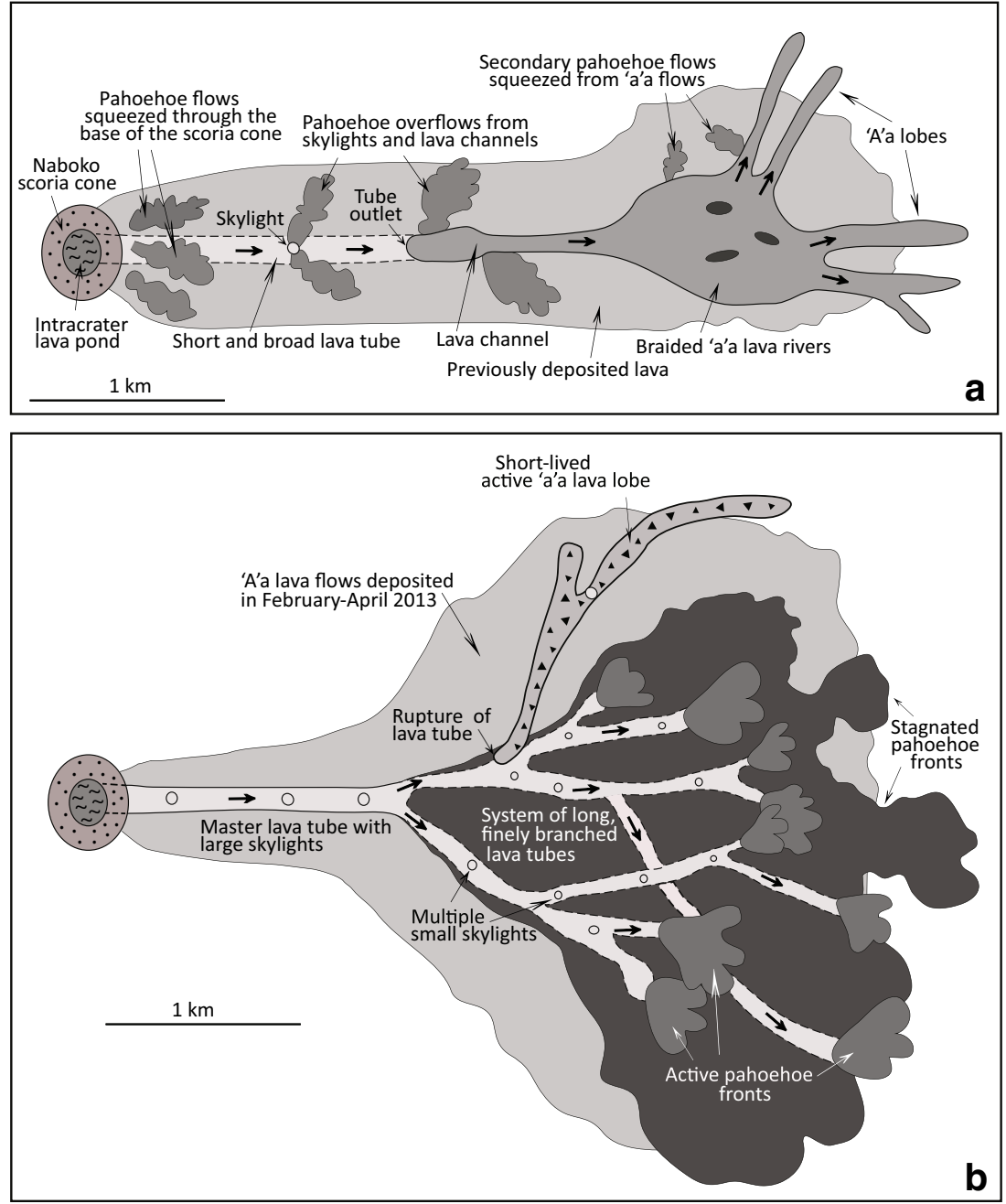

tubes, having multiple fine branches with small outlets (Fig. 10b). Short tubes that formed first provided a localized and concentrated high lava discharge that fed rapid lava streams in open channels. These channels provided the conditions for rapid cooling and autobrecciation of the surface layer of the flowing lava, which thus obtained a high viscosity and yield strength. The thickness of this upper layer gradually increased with flow distance, and the distal flow lobes were composed almost entirely of highly viscous cohesive lava autobreccia that determined the 'a' a style of flow propagation. In contrast, the long, finely branched tubes that formed later distributed lava to multiple boccas with low-discharge rates, and ensured negligible cooling of the transported lava. Lowdischarge effusion favored the formation and preservation of thin, viscous skin on the lava surface, allowing the flow lobes to inflate like a balloon and propagate by pahoehoe style.

The described evolution of the transport system became possible due to rapid accumulation of a thick sequence of partly solidified lava flows over the area of the Toludskoye lava field. The first flows that quickly covered almost the entire area of the field in February-April were mostly of 'a'a type (fed by short and broad tubes). Later, in May-July, lava intruded into still-molten internal cores of the 'a'a flows, elongating the tubes and building multiple small branches of the tube system. One of these intrusions was documented with the time-lapse camera (Online Resource Video ESM 7). The video demonstrated that the 'a'a flow front (that was completely inactive for at least 2.5 days since the camera was installed) started to bulge upward in one isolated location approximately $10 \mathrm{~m}$ across. The bulge slowly inflated up to the height of $2 \mathrm{~m}$ over $1.5 \mathrm{~h}$, then streams of fluid lava poured out from its base forming several long pahoehoe flows. The instantaneous local effusion rate was so high that flows of slabby pahoehoe formed.

Intrusions of lava probably occurred during blockages of the tubes by "lava boats," when the hydrostatic pressure of lava in the tubes abruptly increased upstream from the blockages (such pressurization events were indicated by formation of shatter rings and tumuli). These small branches started to feed the pahoehoe flows of the lava field. Later, inflating pahoehoe sheets provided additional subsurface paths for lava to feed the most distal pahoehoe flows of the lava field. A 
similar process was observed during long-lasting effusion of Kilauea volcano in 1969-1971 (Swanson 1973). Physical models have shown that such intrusions (or viscous fingering) start to occur when a lava field grows and its surface area increases (Anderson et al. 2005).

\section{Lava flow models}

\section{'A'a flow model}

The studied 'a'a lobes visually looked like gravity flows with a Bingham fluid rheology, as is consistent with Hulme (1974), Park and Iversen (1984), Blake (1990), and Dragoni et al. (1992). However, the discovered complex patterns of the surface and flow front velocities observed here (Fig. 5) cannot be explained by such simple model alone. Our data are summarized in the following proposed two-layered model of the 'a'a flows (Fig. 11). In this model, the molten core of a propagating 'a'a lobe consists of two layers of lava with contrasting rheological properties (layers 2 and 3 of Fig. 11). It is important to emphasize that both the stagnated basal breccia (layer 1) and the superficial layer of clinker (layer 4) do not play an important role in the mechanics of the 'a'a flows and are not considered here. The lower layer of the molten core is composed of fluid lava having a quasi-Newtonian rheology with a viscosity around $10^{4} \mathrm{~Pa}$. This material, when squeezed from the internal parts of the 'a' a flows, formed secondary pahoehoe flows. The upper layer of the molten core is composed of highly viscous, partly molten, cohesive lava autobreccia with a quasi-Bingham rheology. Viscosity of the upper layer was not measured directly, but it is probably equal to, or somewhat higher than $10^{6} \mathrm{~Pa} \mathrm{~s}$, this being the viscosity determined by the flow rate method for the frontal parts of the 'a'a flows, which, in most cases, was composed entirely of such high-viscosity material. The upper viscous layer has a high yield strength estimated at $8600 \mathrm{~N} / \mathrm{m}^{2}$. A similar twocomponent structure of 'a'a flows was suggested by Slezin (1990) based on the morphology of lava flows of Klyuchevskoy volcano.

The two-layered structure forms early in the flow process, as soon as lava leaves an outlet of the feeding tube and flows in an open channel with high local effusion rate. In the open channel, the surface layer of the lava undergoes rapid cooling and degassing, both accompanied by dramatic increases in
Fig. 11 Phenomenological model of 'a'a lava lobe dynamics. Thick arrows indicate the direction of the lava flows; lengths of the arrows are proportional to flow velocity. The scale is approximate

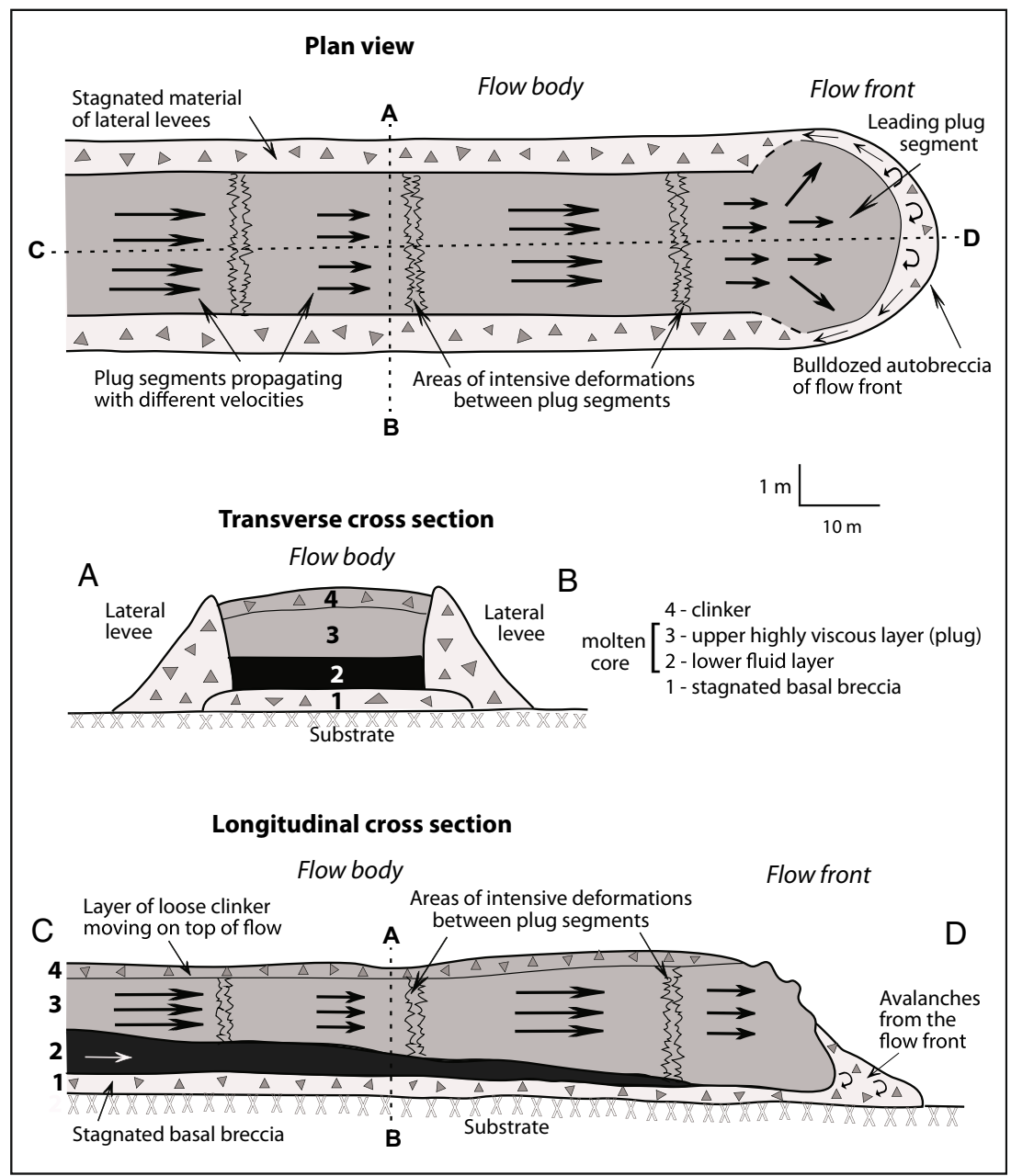


viscosity (e.g., Crisp and Baloga 1990), and simultaneous intensive flow-induced deformations (Fig. 4b, d), transforming this layer into a cohesive mixture of viscous melt and autobrecciated solidified lava. The underlying layer of lava cools and degasses much slower and preserves high temperatures and low viscosities. Due to vesiculation and brecciation, the upper part of the molten core is less dense than its lower part, and in combination with the mostly laminar character of the flow, this density contrast prevents intermixing of the two layers. Lateral bounding by the levees does not allow the two layers to spread laterally. A similar viscosity contrast between surface and interior lava was described for the Pohue Bay flow of Mauna Loa by Jurado-Chichay and Rowland (1995).

The relative thicknesses of the two layers change with travel distance. The lower fluid layer composes nearly $100 \%$ of the flow thickness in the lava channel near the outlet of the feeding tube and gradually decreases toward the ' $a$ 'a flow front; the upper layer simultaneously increases its thickness and comprises the entire front of the 'a'a lobe.

On the surface of mature/distal ' $a$ 'a lobes, the upper layer forms a thick viscous plug that glides toward the flow front over a relatively thin lower layer of fluid lava, the lower layer effectively working as a lubricant. In the flow front area, the plug overrides the lower fluid layer of lava, and the entire thickness of the flow core is composed of partly molten cohesive lava breccia of the plug. The plug is not coherent over the whole length of the flow. Instead, it is broken into transverse segments several tens of meters long, where flow-induced deformation is concentrated in between the segments. These segments glide over the lower fluid layer with somewhat different velocities. The plug segments probably form in response to deformation (bending) of the flow body caused by its curvilinear motion over the topography and/or the necessity to accommodate different flow velocities along the flow path, which in turn are caused by fluctuations of lava discharge at the source, changes of local slope inclinations, and various dynamic processes in the flow.

The velocity of each segment fluctuates by a factor up to 5 with time and distance independently of the velocities of neighboring segments. Mechanical interactions between multiple moving plug segments probably determine the observed complex patterns of surface and front velocities of the flow (Fig. 5). Some of the observed short-period quasi-periodic accelerations and decelerations can be caused by peculiarities of frictional interactions of the plug segments with basal breccia and/or lateral levees of the flow, e.g., by a stick-slip effect (e.g., Ozerov 2000). Similar fluctuations were described for the 2004-2005 'a' a flows of Etna (James et al. 2007).

The plug segments, in accordance with their relative velocities, experience compression or extension, with corresponding changes in their thicknesses. The frontal segment of the plug being pushed forward by the trailing plug segments is able to propagate over horizontal areas, or even upslope for short distances, as was observed, for example, during flow on March 18, 2013.

The terms "conveyor belt" and "caterpillar-track" motion are widely used to describe the mechanics of 'a'a lobes (e.g., Krauskopf 1948; Lipman and Banks 1987; Francis 1993; Harris and Rowland 2001). However, material of the plug has limited ability for plastic deformation. Thus, upon reaching the flow front area, it cannot bend down and roll over the flow snout like a conveyer belt. The frontal segment motion would be more accurately described as a continuous forward-extrusion of the plug-forming material (Macdonald 1953; Kilburn and Guest 1993). The extruding material crumbles into pieces that form marginal levees and basal breccia of the flow. This loss of material results in a systematically slower velocity of the flow snout propagation in comparison with the surface velocity of the flow body.

The 'a'a flow lobe stagnates when the friction along basal and lateral contacts of the upper layer exceeds the driving gravitational force. If lava continues to discharge from the feeding lava tube, a new 'a'a lobe will branch off higher upstream behind the stagnated lobe. The lower layer of the stagnated flow is insulated by the upper layer above, basal breccia below, and by lateral levees. It continues to remain molten for several days to weeks, and possibly months. New portions of fluid lava can thus continue to intrude into the still-molten lower layer and turn 'a'a into a lava-feeding lava tube. This mechanism explains the observed extrusions of pahoehoe lavas from long-stagnated 'a'a flows.

\section{Pahoehoe flow model}

Data collected for the 2013 pahoehoe flows of Tolbachik are placed in the model in Fig. 12. When lava extrudes with a low effusion rate, its surface layer undergoes cooling, degassing, and gradual solidification (Fig. 4c, e) but also slowly deforms, too slowly to experience autobrecciation. Our measurements demonstrate that $1 \mathrm{~min}$ after initial exposure the lava has a surface layer $1-2 \mathrm{~cm}$ thick with a viscosity several times higher than that of the underlying lava, forming the lobe skin (Fig. 9). This skin deforms plastically and acts like a ballooning envelope: the continuing slow input of new volumes of fluid lava into the lobe causes internal pressurization and gradual inflation (Hon et al. 1994). The higher the skin viscosity and the skin thickness, the less the lobe behaves as a gravity flow, and the more it resembles the inflation of a balloon. In cases with a very viscous skin develops, the lava lobes obtain an almost spherical shape (Fig. 6).

Lobe inflation causes stretching of the skin. The stretching is not uniform over the surface area of the growing lobe. Instead, it is concentrated along a spreading structure where new flexible skin forms. Localization of the spreading structure either on the upper surface at the rear of the lobe 
Fig. 12 Phenomenological models of pahoehoe lava lobe dynamics by a rear growth mode and $\mathbf{b}$ frontal growth mode. Double arrow indicates the direction of the lobe propagation. Inset shows the growing lobe chain with the square outlining the area enlarged in $\mathbf{a}$ and $\mathbf{b}$. The scale is approximate; thickness of lava crust exaggerated

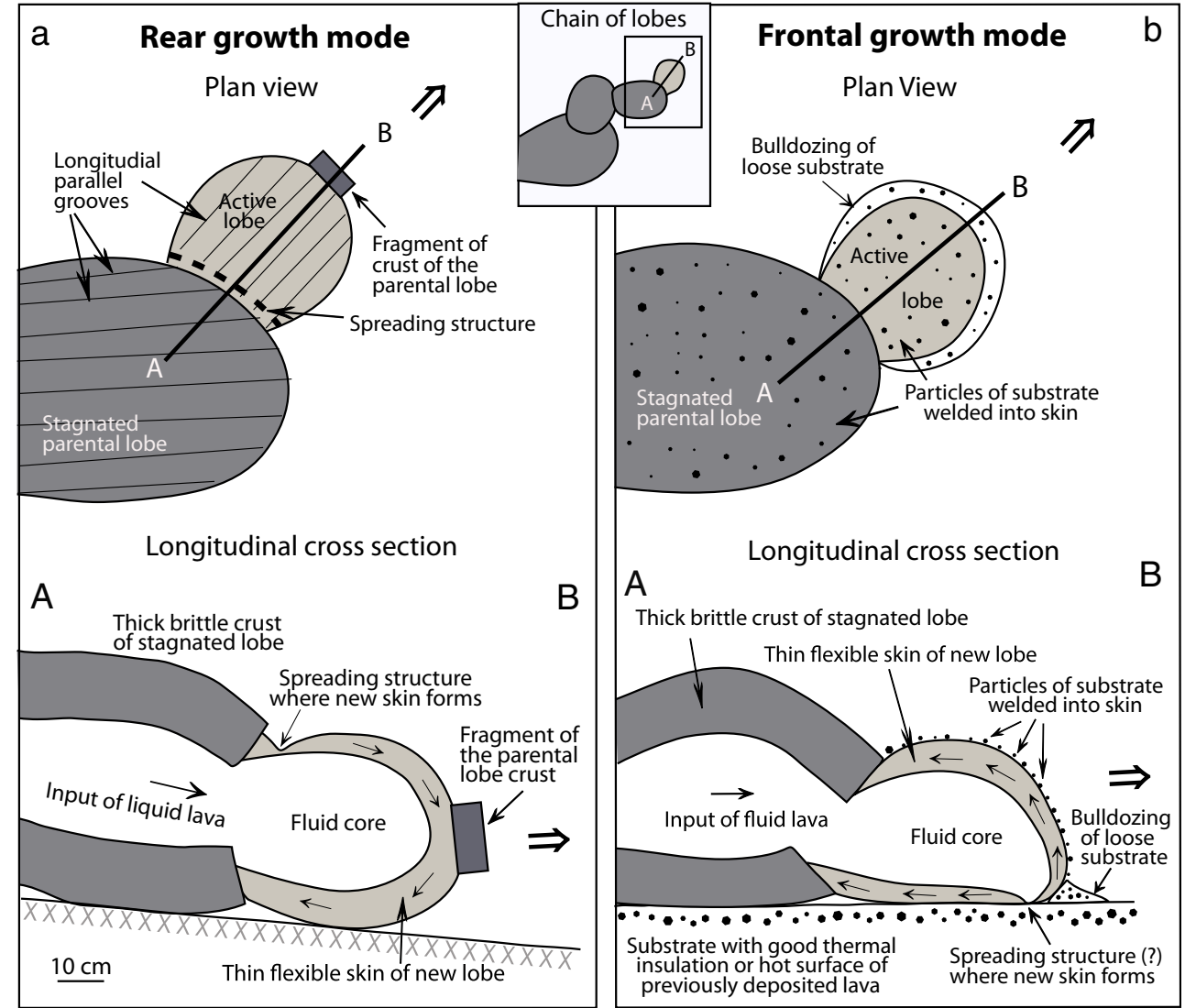

(Fig. 12a), or along the basal surface close to the lobe front (Fig. 12b), results in two different modes of lobe growth. The mode of lobe growth strongly depends on thermal insulation properties and the temperature of the substrate, and probably also on temperature of ambient air (e.g., Keszthelyi and Denlinger 1996). Similarly, two modes of lobe growth are clearly visible on videos of active pahoehoe flows in Hawaii (e.g., a lobe with the frontal growth mode is shown on Fig. 1 of Hoblitt et al. 2012). Due to thinner lava skin and faster advancing rates of these lobes, in comparison with those of Tolbachik, the two modes frequently switch from one to the other, even during the growth of one lobe. Gregg and Keszthelyi (2004) described a range of emplacement styles associated with variations in local effusion rate during the 1996 of Kilauea. Their "swelling lobes" are rather similar to the lobes with frontal growth mode of Tolbachik, and their "cracking lobes" are similar to the lobes with rear growth mode.

To inflate, the lobe must have stretchable and flexible skin (Hon et al. 1994). Progressive cooling and degassing of the skin of the growing lobe gradually increases its thickness and viscosity (stiffness) with time, but the continuing formation of new flexible skin, occurring along the spreading structure, allows the lobe to inflate. The rate of lobe growth, and hence, the rate of surface area increase and the rate of formation of new skin in the spreading structure, is highest while the lobe is small, but progressively slows as the lobe volume increases due to conservation of the volume to surface area relation. Because of this, the stiffness of the lobe skin progressively increases with time and retards the input of lava into the growing lobe, additionally decreasing the rate of new skin formation that produces negative feedback. As a consequence of the two processes, while the rate of lobe growth slows down exponentially with time (Fig. 7), its internal pressure increases (the pressure can additionally grow due to local exsolution of volatiles from lava into gas bubbles). At some point, the skin, which becomes too stiff to deform plastically, mechanically fails and the next lobe starts to extrude through the opening fracture. In our case, this process occurs repeatedly and results in the sequential formation of a chain of hydraulically connected lobes. The longer the chain, the higher the hydraulic resistance to the lava flowing through it. Thus, the chain grows to a certain length (commonly between three and seven connected lobes), and at some point, lava breaks out closer to the lava source and the new chain of lobes starts to form.

The interlacing chains composed of growing lava lobes form the outer front of the propagating pahoehoe field. The observed uniform uplift of the upper surface of such fields during the process of secondary postemplacement inflation indicates that, after initial emplacement, fluid molten cores 
of individual flow lobes and lobe chains merge together/ coalesce over broad areas. During the process of postemplacement, inflation lateral margins of neighboring flow lobes probably fracture and/or remelt, allowing their molten cores to coalesce (Hon et al. 1994). Thus, the propagating front of the pahoehoe field composed of growing but isolated chains of lobes is followed, at some distance behind, by inflation-related sill-like intrusion of lava. As a result, the upper rigid crust of the pahoehoe field rests/floats over a broad, uninterrupted layer of fluid lava.

\section{Conclusions}

Our investigations demonstrate that the observed gradual transition from the dominant ' $a$ ' a to dominant pahoehoe propagation style during the formation of the Toludskoye lava field of the 2012-2013 Tolbachik eruption was caused solely by and occurred simultaneously with progressive elongation and branching of the system of feeding lava tubes. This became possible due to rapid accumulation of a thick pile of partly solidified lava flows that provided a favorable environment for shallow subsurface intrusions and migrations of lava, which, with time, developed into branches of the lava tube system. We conclude that the emplacement style of highdischarge long-lasting effusions of fluid lava, including flood basalts, with time naturally, without the necessity of changes of the effusion parameters, evolves from 'a' a to pahoehoe.

We have found that both 'a' a and pahoehoe flows have a complex internal structure comprised of layers of lava with contrasting rheological properties. The approximation of a lava flow as a body having a homogeneous rheology of any kind (Newtonian, Bingham, of whatsoever) is thus misleading. The studied 'a'a lobes were composed of a lower fluid layer with quasi-Newtonian properties and an upper highly viscous layer with quasi-Bingham properties. This twolayered flow was enveloped in thick mantle of granular material. Pahoehoe lobes had cores, composed of fluid lava with quasi-Newtonian properties, that inflated while being enveloped into a viscous skin, with quasi-Bingham properties, that gradually solidified into a brittle material. If an advancing lava lobe abruptly changes its propagation style from 'a'a to pahoehoe, or vice versa, this does not necessarily indicate transition from one rheological behavior to another due to changes of viscosity, yield strength, strain rate, etc. Such transitions occur when the previously established layered structure of the flow lobe mechanically fails due to gravitational collapse on a steep slope, buildup of internal hydrostatic pressure, etc., and the internal layer of fluid lava suddenly breaks out and continues to propagate farther down slope independently of the outer more viscous layers. 'A'a lava transitions to the pahoehoe type when its internal low viscous layer of lava breaks out with a low effusion rate. Pahoehoe flow transitions to the 'a'a flow type when its internal low viscous lava breaks out with high effusion rate. To a significant extent, the resulting complex propagation dynamics of 'a' a and pahoehoe lobes arises from their complex internal structure composed of layers of lava with contrasting rheological properties.

Acknowledgments We thank Sergey Chirkov and Irina Dubrovskaya for providing FLIR images of the lava flows of the 2013 eruption, as well as Janine Krippner for English language improvement of the manuscript. The suggestions of Steve Anderson, the anonymous reviewer, the handling editor Jacopo Taddeucci, and executive editor Andrew Harris were extremely helpful.

Funding information This research was funded by the Institute of Volcanology and Seismology of the Russian Academy of Sciences and in part by the grant of the National Science Foundation (NSF-RAPID 0910712).

\section{References}

Anderson SW, Stofan ER, Smrekar SE, Guest JE, Wood B (1999) Pulsed inflation of pahoehoe lava flows: implications for flood basalt emplacement. Earth Planet Sci Lett 168(1):7-18. https://doi.org/10. 1016/S0012-821X(99)00044-8

Anderson SW, McColley SM, Fink JH, Hudson RK (2005) The development of fluid instabilities and preferred pathways in lava flow interiors. In: Manga M and Ventura $G$ (eds). Insights from analog experiments and fractal analysis, in kinematics and dynamics of lava flows, Geol Soc Amer Spec Pap 396:147-161

Andreev VI, Gusev NA, Kovalev GN, Slezin YB (1978) Dynamics of lava flows of southern breakthrough of great Tolbachik fissure eruption, 1975-76. Bull Volcanol Stations 55:18-26 (in Russian)

Ballard RD, Moore JG (2012) Photographic atlas of the mid-Atlantic Ridge rift valley. Springer, Berlin

Belousov A, Belousova M, Edwards B, Volynets A, Melnikov D (2015) Overview of the precursors and dynamics of the 2012-13 basaltic fissure eruption of Tolbachik Volcano, Kamchatka, Russia. J Volcanol Geotherm Res 307:22-37. https://doi.org/10.1016/j. jvolgeores.2015.06.013

Blake S (1990) Viscoplastic models of lava domes. In: Fink J (ed) Lava flows and domes. Emplacement mechanisms and hazard implications. Springer, Berlin, pp 88-126

Bottinga Y, Weill DF (1972) The viscosity of magmatic silicate liquids: a model calculation. Am J Sci 272(5):438-475. https://doi.org/10. 2475/ajs.272.5.438

Chaplygin IV, Lavrushin VY, Dubinina EO, Bychkova YV, Inguaggiato S, Yudovskaya MA (2016) Geochemistry of volcanic gas at the 2012-13 New Tolbachik eruption, Kamchatka. J Volcanol Geotherm Res 323:186-193. https://doi.org/10.1016/j.jvolgeores. 2016.04.005

Crisp J, Baloga S (1990) A model for lava flows with two thermal components. J Geoph Res: Solid Earth 95(B2):1255-1270. https://doi. org/10.1029/JB095iB02p01255

Dingwell DB (2006) Transport properties of magmas: diffusion and rheology. Elements 2(5):281-286. https://doi.org/10.2113/gselements.2.5.281

Dragoni M, Pondrelli S, Tallarico A (1992) Longitudinal deformation of a lava flow: the influence of Bingham rheology. J Volcanol Geotherm Res 52(4):247-254. https://doi.org/10.1016/0377-0273(92)90047-H

Dvigalo VN, Svirid IY, Shevchenko AV (2014) The first quantitative estimates of parameters for the Tolbachik fissure eruption of 2012-2013 from aerophotogrammetric observations. J Volcanol Seismol 8(5):261-268 
Edwards BR, Belousov A, Belousova M (2014) Propagation style controls lava-snow interactions. Nat Commun 5:5666

Edwards BR, Belousov A, Belousova M, Melnikov D (2015) Observations on lava, snowpack and lava-snowpack interactions during the 2012-13 Tolbachik eruption, Klyuchevskoy Group of Volcanoes, Kamchatka, Russia. J Volcanol Geotherm Res 307: 107-119. https://doi.org/10.1016/j.jvolgeores.2015.08.010

Einarsson T (1966) Studies of temperature, viscosity, density and some types of materials produced in the Surtsey eruption. Surtsey Res Progr Rep 1:163-179

Fedotov SA, Markhinin YK (eds) (1983) The great Tolbachik fissure eruption, 1975-1976. Cambridge University Press, New York 341 $\mathrm{pp}$

Fink JH, Zimbelman JR (1986) Rheology of the 1983 Royal Gardens basalt flows, Kilauea volcano, Hawaii. Bull Volcanol 48(2-3):8796. https://doi.org/10.1007/BF01046544

Francis P (1993) Volcanoes. A planetary perspective. Clarendon, Oxford $452 \mathrm{p}$

Gauthier F (1973) Field and laboratory studies of the rheology of Mount Etna lava. Phil Trans Royal Soc Lond A: Math, Phys, Eng 274(1238):83-98. https://doi.org/10.1098/rsta.1973.0028

Giordano D, Russell JK, Dingwell DB (2008) Viscosity of magmatic liquids: a model. Earth Planet Sci Lett 271(1):123-134. https://doi. org/10.1016/j.epsl.2008.03.038

Gregg TK, Keszthelyi LP (2004) The emplacement of pahoehoe toes: field observations and comparison to laboratory simulations. Bull Volcanol 66(5):381-391

Griffiths RW (2000) The dynamics of lava flows. Annu Rev Fluid Mech 32(1):477-518. https://doi.org/10.1146/annurev.fluid.32.1.477

Guest JE, Duncan AM, Stofan ER, Anderson SW (2012) Effect of slope on development of pahoehoe flow fields: evidence from Mount Etna. J Volcanol Geotherm Res 219:52-62

Harris AJL, Rowland S (2001) FLOWGO: a kinematic thermorheological model for lava flowing in a channel. Bull Volcanol 63(1):20-44. https://doi.org/10.1007/s004450000120

Harris AJL, Dehn J, Calvari S (2007) Lava effusion rate definition and measurement: a review. Bull Volcanol 70(1):1-22. https://doi.org/ 10.1007/s00445-007-0120-y

Harris AJL, Rowland SK, Villeneuve N, Thordarson T (2017) Pahoehoe, 'a'a, and block lava: an illustrated history of the nomenclature. Bull Volcanol 79(1):7-41. https://doi.org/10.1007/s00445-016-1075-7

Hoblitt RP, Orr TR, Heliker C, Denlinger RP, Hon K, Cervelli PF (2012) Inflation rates, rifts, and bands in a pāhoehoe sheet flow. Geosphere 8(1):179-195. https://doi.org/10.1130/GES00656.1

Hon K, Kauahikaua J, Denlinger R, Mackay K (1994) Emplacement and inflation of pahoehoe sheet flows: observations and measurements of active lava flows on Kilauea Volcano, Hawaii. Geol Soc Am Bull 106(3):351-370. https://doi.org/10.1130/0016-7606(1994) 106<0351:EAIOPS >2.3.CO;2

Hulme G (1974) The interpretation of lava flow morphology. Geoph J Intern 39(2):361-383. https://doi.org/10.1111/j.1365-246X.1974. tb05460.x

James MR, Bagdassarov N, Müller K, Pinkerton H (2004) Viscoelastic behaviour of basaltic lavas. J Volcanol Geotherm Res 132(2):99 113. https://doi.org/10.1016/S0377-0273(03)00340-8

James MR, Pinkerton H, Robson S (2007) Image-based measurement of flux variation in distal regions of active lava flows. Geochem Geophys Geosyst 8(3). https://doi.org/10.1029/2006GC001448

Jeffreys H (1925) The flow of water in an inclined channel of rectangular section. Philos Mag J Sci 49(293):793-807

Jurado-Chichay Z, Rowland SK (1995) Channel overflows of the Pōhue Bay flow, Mauna Loa, Hawai'i: examples of the contrast between surface and interior lava. Bull Volcanol 57(2):117-126. https://doi. org/10.1007/BF00301402
Keszthelyi L, Denlinger R (1996) The initial cooling of pahoehoe flow lobes. Bull Volcanol 58(1):5-18. https://doi.org/10.1007/ s004450050121

Kilburn CRJ (1993) Lava crusts, aa flow lengthening and the pahoehoeaa transition. In: Kilburn CRJ, Luongo G (eds) Active lavas. UCL Press Limited, London, pp 263-280

Kilburn CRJ (2000) Lava flows and flow fields. In: Sigurdsson H (editorin-chief) Encyclopedia of volcanoes, Academic, San Diego, p 291305

Kilburn CRJ, Guest JE (1993) Aa lavas of Mount Etna, Sicily. In: Active lavas. UCL, London, pp 73-106

Krauskopf KB (1948) Lava movement at Paricutin volcano, Mexico. Geol Soc Am Bull 59(12):1267-1284. https://doi.org/10.1130/ 0016-7606(1948)59[1267:LMAPVM]2.0.CO;2

Lev E, James MR (2014) The influence of cross-sectional channel geometry on rheology and flux estimates for active lava flows. Bull Volcanol 76(7):829. https://doi.org/10.1007/s00445-014-0829-3

Lipman PW, Banks NG (1987) AA flow dynamics, Mauna Loa 1984. US Geol Surv Prof Pap 1350:1527-1567

MacDonald GA (1953) Pahoehoe, aa, and block lava. Am J Sci 251(3): 169-191. https://doi.org/10.2475/ajs.251.3.169

MacDonald GA (1963) Physical properties of erupting Hawaiian magmas. Geol Soc Am Bull 74(8):1071-1078. https://doi.org/10. 1130/0016-7606(1963)74[1071:PPOEHM]2.0.CO;2

Manga M, Loewenberg M (2001) Viscosity of magmas containing highly deformable bubbles. J Volcanol Geotherm Res 105(1):19-24. https://doi.org/10.1016/S0377-0273(00)00239-0

Minakami T (1951) On the temperature and viscosity of the fresh lava extruded in the 1951 Oo-sima eruption. Bull Earthq Res Inst 29: 485-498

Moore HJ (1987) Preliminary estimates of the rheological properties of 1984 Mauna Loa lava. US Geol Surv Prof Pap 1350:1569-1588

Naboko SI (1947) Bilyukai Eruption in 1938. Tr Lab Vulkanol 5:122134

Naranjo JA, Sparks RSJ, Stasiuk MV, Moreno H, Ablay GJ (1992) Morphological, structural and textural variations in the 1988-1990 andesite lava of Lonquimay Volcano, Chile. Geol Mag 129(06): 657-678. https://doi.org/10.1017/S0016756800008426

Nichols RL (1939) Viscosity of lava. J Geol 47(3):290-302. https://doi. org $/ 10.1086 / 624778$

Ozerov AY (2000) The evolution of high-alumina basalts of the Klyuchevskoy volcano, Kamchatka, Russia, based on microprobe analyses of mineral inclusions. J Volcanol Geotherm Res 95(1):6579. https://doi.org/10.1016/S0377-0273(99)00118-3

Panov VK, Slezin YB, Storcheus AV (1988) Mechanical properties of lava extruded in the 1983 Predskazanny eruption (Klyuchevskoi volcano). J Volcanol Seismol 7:25-37

Papale P (1999) Strain-induced magma fragmentation in explosive eruptions. Nature 397(6718):425-428. https://doi.org/10.1038/17109

Park S, Iversen JD (1984) Dynamics of lava flow: thickness growth characteristics of steady two-dimensional flow. Geophys Res Lett 11(7):641-644. https://doi.org/10.1029/GL011i007p00641

Peterson DW, Tilling RI (1980) Transition of basaltic lava from pahoehoe to aa, Kilauea Volcano, Hawaii: field observations and key factors. J Volcanol Geotherm Res 7(3-4):271-293. https://doi.org/10.1016/ 0377-0273(80)90033-5

Petford N (2009) Which effective viscosity? Mineral Mag 73(2):167191. https://doi.org/10.1180/minmag.2009.073.2.167

Piip BI (1946) A new flank crater on Plosky Tolbachik Volcano. Bull Vol Obs Kamchatka 13:10-21 (in Russian)

Pinkerton H, Norton G (1995) Rheological properties of basaltic lavas at sub-liquidus temperatures: laboratory and field measurements on lavas from Mount Etna. J Volcanol Geotherm Res 68(4):307-323. https://doi.org/10.1016/0377-0273(95)00018-7

Pinkerton H, Sparks RSJ (1978) Field measurements of the rheology of lava. Nature 276(5686):383-385. https://doi.org/10.1038/276383a0 
Pinkerton H, Herd RA, Kent RM, Wilson L (1995) Field measurements of the rheological properties of basaltic lavas. Lunar Planet Sci Conf 26:1127

Plechov P, Blundy J, Nekrylov N, Melekhova E, Shcherbakov V, Tikhonova MS (2015) Petrology and volatile content of magmas erupted from Tolbachik Volcano, Kamchatka, 2012-13. J Volcanol Geotherm Res 307:182-199. https://doi.org/10.1016/j.jvolgeores. 2015.08.011

Portnyagin M, Duggen S, Hauff F, Mironov N, Bindeman I, Thirlwall M, Hoernle K (2015) Geochemistry of the Late Holocene rocks from the Tolbachik volcanic field, Kamchatka: towards quantitative modelling of subduction-related open magmatic systems. J Volcanol Geotherm Res 307:133-155. https://doi.org/10.1016/j. jvolgeores.2015.08.015

Proussevitch AA, Sahagian DL (1998) Dynamics and energetics of bubble growth in magmas: analytical formulation and numerical modeling. J Geophys Res Solid Earth 103(B8):18223-18251. https://doi. org/10.1029/98JB00906

Rowland SK, Walker GP (1987) Toothpaste lava: characteristics and origin of a lava structural type transitional between pahoehoe and 'a'a. Bull Volcanol 49(4):631-641. https://doi.org/10.1007/ BF01079968

Rowland SK, Walker GP (1988) Mafic-crystal distributions, viscosities, and lava structures of some Hawaiian lava flows. J Volcanol Geotherm Res 35(1-2):55-66. https://doi.org/10.1016/03770273(88)90005-4

Rowland SK, Walker GP (1990) Pahoehoe and aa in Hawaii: volumetric flow rate controls the lava structure. Bull Volcanol 52(8):615-628. https://doi.org/10.1007/BF00301212

Saar MO, Manga M, Cashman KV, Fremouw S (2001) Numerical models of the onset of yield strength in crystal-melt suspensions. Earth Planet Sci Lett 187(3):367-379. https://doi.org/10.1016/S0012821X(01)00289-8

Self S, Keszthelyi L, Thordarson T (1998) The importance of pahoehoe. Annu Rev Earth Planet Sci 26(1):81-110. https://doi.org/10.1146/ annurev.earth.26.1.81

Shaw HR, Wright TL, Peck DL, Okamura R (1968) The viscosity of basaltic magma; an analysis of field measurements in Makaopuhi lava lake, Hawaii. Am J Sc 266(4):225-264. https://doi.org/10. 2475/ajs.266.4.225
Slezin YB (1990) The morphology and rheology of modern Klyuchevskoi parasitic lava flows. J Volcanol Seismol 10:665-686

Soldati A, Sehlke A, Chigna G, Whittington A (2016) Field and experimental constraints on the rheology of arc basaltic lavas: the January 2014 eruption of Pacaya (Guatemala). Bull Volcanol 78(6):1-19

Soule SA, Cashman KV, Kauahikaua JP (2004) Examining flow emplacement through the surface morphology of three rapidly emplaced, solidified lava flows, Kîlauea Volcano, Hawai'i. Bull Volcanol 66(1):1-14. https://doi.org/10.1007/s00445-003-0291-0

Sparks RSJ (2004) Dynamics of magma degassing. Volcanic degassing. Geol Soc Lond Spec Pub 213:5-22

Swanson DA (1973) Pahoehoe flows from the 1969-1971 Mauna Ulu eruption, Kilauea volcano, Hawaii. Geol Soc Am Bull 84(2):615626. https://doi.org/10.1130/0016-7606(1973)84<615:PFFTMU>2. $0 . \mathrm{CO} ; 2$

Vande-Kirkov YV (1978) Viscosity of the lavas of the Northern Breakthrough (Tolbachik), 1975. Bull Volcanol Stations 55:13-17

Volynets AO, Edwards BR, Melnikov D, Yakushev A, Griboedova I (2015) Monitoring of the volcanic rock compositions during the 2012-2013 fissure eruption at Tolbachik volcano, Kamchatka. J Volcanol Geotherm Res 307:120-132. https://doi.org/10.1016/j. jvolgeores.2015.07.014

Vona A, Romano C, Dingwell DB, Giordano D (2011) The rheology of crystal-bearing basaltic magmas from Stromboli and Etna. Geochim Cosmochim Acta 75(11):3214-3236. https://doi.org/10.1016/j.gca. 2011.03.031

Walker GPL (1967) Thickness and viscosity of Etnean lavas. Nature 213(5075):484-485. https://doi.org/10.1038/213484a0

Walker GP (1991) Structure, and origin by injection of lava under surface crust, of tumuli, "lava rises", "lava-rise pits", and "lava-inflation clefts”. Hawaii Bull Volcanol 53(7):546-558. https://doi.org/10. 1007/BF00298155

Walker GPL, Huntingdon AT, Sanders AT, Dinsdale JL (1973) Lengths of lava flows [and discussion]. Phil Trans Royal Soc Lond A: Math, Phys, Eng 274(1238):107-118. https://doi.org/10.1098/rsta.1973. 0030

Wilson L, Head JW (2007) Heat transfer in volcano-ice interactions on Earth. Ann Glaciol 45:83-86. https://doi.org/10.3189/ 172756407782282507 